\title{
Anti-trichomonad activities of different compounds from foods, marine products, and medicinal plants: a review
}

\author{
Mendel Friedman ${ }^{1 *}$ (D), Christina C. Tam², Luisa W. Cheng ${ }^{2}$ and Kirkwood M. Land ${ }^{3}$
}

\begin{abstract}
Human trichomoniasis, caused by the pathogenic parasitic protozoan Trichomonas vaginalis, is the most common non-viral sexually transmitted disease that contributes to reproductive morbidity in affected women and possibly to prostate cancer in men. Tritrichomonas foetus strains cause the disease trichomoniasis in farm animals (cattle, bulls, pigs) and diarrhea in domestic animals (cats and dogs). Because some T. vaginalis strains have become resistant to the widely used drug metronidazole, there is a need to develop alternative treatments, based on safe natural products that have the potential to replace and/or enhance the activity of lower doses of metronidazole. To help meet this need, this overview collates and interprets worldwide reported studies on the efficacy of structurally different classes of food, marine, and medicinal plant extracts and some of their bioactive pure compounds against T. vaginalis and T. foetus in vitro and in infected mice and women. Active food extracts include potato peels and their glycoalkaloids a-chaconine and a-solanine, caffeic and chlorogenic acids, and quercetin; the tomato glycoalkaloid atomatine; theaflavin-rich black tea extracts and bioactive theaflavins; plant essential oils and their compounds (+)-abisabolol and eugenol; the grape skin compound resveratrol; the kidney bean lectin, marine extracts from algae, seaweeds, and fungi and compounds that are derived from fungi; medicinal extracts and about 30 isolated pure compounds. Also covered are the inactivation of drug-resistant T. vaginalis and T. foetus strains by sensitized light; antitrichomonad effects in mice and women; beneficial effects of probiotics in women; and mechanisms that govern cell death. The summarized findings will hopefully stimulate additional research, including molecular-mechanism-guided inactivations and human clinical studies, that will help ameliorate adverse effects of pathogenic protozoa.
\end{abstract}

Keywords: Trichomonas vaginalis, Tritrichomonas foetus, Trichomoniasis, Trichomonosis, Rodent and human studies, Food compounds, Marine compounds, Medicinal plant compounds, Anti-trichomonad effects, Mechanisms

\section{Background}

The flagellate protozoan Trichomonas vaginalis is an extracellular parasite that infects the vagina and the male genital tract causing the most common non-viral sexually transmitted human venereal disease (STD) trichomoniasis, with about 300 million annual cases worldwide and about 3.7 million in the United States [1-3].

\footnotetext{
* Correspondence: Mendel.Friedman@ars.usda.gov

1 United States Department of Agriculture, Healthy Processed Foods Research Unit, Agricultural Research Service, Albany, CA 94710, USA

Full list of author information is available at the end of the article
}

The mostly asymptomatic disease does not seem to decrease with age, reaching a maximum rate in 48-51-year old women [4]. Metronidazole (5-nitroimidazole) seems to be the one of the few available synthetic drugs used clinically to treat trichomoniasis. Coinfection with other STDs is common; chlamydia, gonorrhea, and syphilis are other STDs that cause major health problems, especially in tropical and subtropical developing countries [5]. Tritrichomonas foetus strains cause trichomonosis, STDs in cattle [6], and pigs [7], and diarrhea in cats and dogs [8-10].

C C The Author(s). 2020 Open Access This article is licensed under a Creative Commons Attribution 4.0 International License, which permits use, sharing, adaptation, distribution and reproduction in any medium or format, as long as you give appropriate credit to the original author(s) and the source, provide a link to the Creative Commons licence, and indicate if changes were made. The images or other third party material in this article are included in the article's Creative Commons licence, unless indicated otherwise in a credit line to the material. If material is not included in the article's Creative Commons licence and your intended use is not permitted by statutory regulation or exceeds the permitted use, you will need to obtain permission directly from the copyright holder. To view a copy of this licence, visit http://creativecommons.org/licenses/by/4.0/ The Creative Commons Public Domain Dedication waiver (http://creativecommons.org/publicdomain/zero/1.0/) applies to the data made available in this article, unless otherwise stated in a credit line to the data. 
Because these pathogens are developing resistance to the widely used drug metronidazole and the disease causes numerous unpleasant adverse side effects (allergy, nausea, vomiting, predisposition to cervical cancer, adverse pregnancy outcomes, infertility, and a co-factor in the transmission of the human immunodeficiency virus (HIV), there is an urgent need to develop new effective therapeutic agents against both drug sensitive and resistant trichomonads that might be able to protect against and/or help cure exposed individuals and animals. To help meet this need, this review collates and interprets studies from several countries on reported antitrichomonad properties of a variety of structurally different food, marine, and medicinal, including herbal, plant compounds, as well marine, plant, and fungal extracts containing multiple bioactive compounds. The results of the described efforts suggest that several formulations (pure compounds and extracts) could replace or enhance additively and synergistically the therapeutic potency of metronidazole of 30 anti-trichomonad compounds shown in Table 1 and described in the text.

\section{Vaginal microflora, dysbiosis, disease, and treatment}

Because vaginal dysbiosis is a contributing factor to trichomoniasis in women and because treatments applied vaginally should not upset this important ecosystem, it is worth considering the effects of this dysbiosis and how balance can potentially be restored with biotic treatments. The role of the "normal" microflora has been extensively studied, especially in relation to human gastrointestinal diseases and susceptibility to pathogens and toxins. The dysbiotic microflora environment can be reversed via treatment with prebiotics and/or probiotics such as lactobacilli with beneficial results for a variety of gastrointestinal diseases and reduced susceptibility to pathogens and pathogen products [33]. Dysbiosis or disturbance of this very important microflora in the vagina can lead to many severe adverse conditions including preterm birth, pelvic inflammatory disease, increased risk and transmission of sexually transmitted infections, along with many other health conditions [34]. Therefore, understanding the effects of the vaginal microbiome and its dysregulation on human health and susceptibility to trichomonad infection is of crucial importance. Additionally, researchers must understand the urogenital, and specifically the vaginal environment to safely and effectively deliver therapeutics to target the infection.

A normal vagina is acidic with a $\mathrm{pH}$ of approximately 4 to 4.5 but can vary between 3.5 and 5 . This acidic environment occurs because of the resident microflora. It has been reported that there are five predominant microbiota states or community types (CSTs) that have been isolated from premenopausal women. Four of these CSTs are dominated by Lactobacillus spp. The last CST
(CST-IV), however, does not contain lactobacilli but rather the overgrowth of anaerobic bacteria i.e. Gardnerella vaginalis, Atopobium vaginae, Prevotella bivia, and others [35-37].

The lactobacilli use glycogen from exfoliated epithelial cells, which is converted to lactic and fatty acids. Additionally, these bacteria are able to produce other bactericidal products including hydrogen peroxide, bacteriocins, bacteriocin-like products, and surfactants that help in preventing infections $[38,39]$. Products from various Lactobacillus spp. have been shown to inhibit or reduce adherence of urogenital pathogens via competitive exclusion of the host receptor(s) [38]. Phukan, Brooks [40] described the discovery of an aggregation promoting factor APF-2 from the vaginal strain L. gasseri ATCC 9857 that inhibits $T$. vaginalis adherence to human vaginal ectocervical cells. Hinderfeld, Phukan [37] showed that T. vaginalis and CST-IV associated-bacteria are correlated with $T$. vaginalis infections [41], can enhance paracellular permeability of the cervicovaginal epithelium by dysregulating tight junctions, and affect proinflammatory cytokines such as interleukin-6 (IL-6) and tumor necrosis factor- $\alpha$ (TNF$\alpha)$. Valadkhani et al. indicated the protective role of Lactobacillus acidophilus in $T$. vaginalis infection using healthy human vaginal cells [42]. Restoration of the vaginal microflora by both oral and vaginal delivery of prebiotics, probiotics, and/or synbiotics have been attempted for bacterial vaginosis, as well as for $T$. vaginalis infection, with varying degrees of success dependent on strain(s) used, duration of treatment, route of delivery, and whether in combination with traditional drugs $[39,43]$. This is therefore a potential strategy that could be investigated alongside the natural products that we will describe herein.

\section{Anti-trichomonad compounds in plant-based food}

Plants produce bioactive organic compounds known as secondary metabolites to protect themselves against various diseases caused by phytopathogens as well as by environmental stress conditions such as drought. Some of these compounds are therefore found in plant-based foods and it is known that they also have the potential to protect animals and humans against different pathogenic organisms, including parasitic protozoa.

\section{Potato glycoalkaloids - a-chaconine, a-solanine, and the aglycone solanidine}

Friedman, Huang [14] describe the inactivation, using cell-based assays, of the three pathogenic protozoal strains $T$. vaginalis human G3, Tritrichomonas foetus feline C1, and Tritrichomonas foetus bovine D1 by the potato (Solanum tuberosum) glycoalkaloids $\alpha$-chaconine and $\alpha$-solanine, their common aglycone solanidine, three potato phenolic compounds (Fig. 1), and six potato peel 
Table 1 Inhibition of pathogenic trichomonads by food and medicinal plant compounds listed alphabetically

\begin{tabular}{|c|c|c|c|c|}
\hline Compound & Source & Trichomonad & Inhibition & Reference \\
\hline Benzopyrans & medicinal plant; Hypericum polyanthenum & T. vaginalis & cell damage & [11] \\
\hline Betulinic acid & medicinal plant; Palatanus acerifoli & T. vaginalis & cell growth & [12] \\
\hline (+)-Bisabolol & essential oil; Nectandra megapotamica & T. vaginalis & $\mathrm{IC}_{50} 98.7 \mu \mathrm{g} / \mathrm{mL}$ & [13] \\
\hline Caffeic acid & potatoes; Solanum tuberosum & 3 trichomonads $^{\text {a }}$ & $21.1-42.8 \%$ & {$[14]$} \\
\hline Candimine & ornamental plant; Hippeastrum morelianum & T. vaginalis & cell damage & {$[15]$} \\
\hline Carmaphycin-17 & cancer drug; protesome inhibitor & T. vaginalis & highly active & {$[16]$} \\
\hline a-Chaconine & potatoes; Solanum tuberosum & 3 trichomonads & $\mathrm{IC}_{50} 35-60 \mu \mathrm{M}$ & [14] \\
\hline Chlorogenic acid & potatoes; Solanum tuberosum & 3 trichomonads & $11.4-21.9 \%$ & {$[14]$} \\
\hline Emodin & rhubarb; Rheum palmatum & T. vaginalis & active in mice & {$[17]$} \\
\hline Geraniol & essential oil; Amomum tsao-ko & T. vaginalis & $171-343 \mu \mathrm{g} / \mathrm{mL}$ & [18] \\
\hline Hedargenin & medicinal plant; Cassnia holstii & T. vaginalis & $\mathrm{IC}_{50} 2.8 \mu \mathrm{M}$ & [19] \\
\hline (+)-Isoaustrobrasilol & medicinal plant; Hypericum spp. & T. vaginalis & cell damage & {$[20]$} \\
\hline Lectin & kidney beans; Phaseolus vulgaris & T. vaginalis & cell damage & [21] \\
\hline Lucidin-isopropyl-ether & plant roots; Morinda panamensis & T. vaginalis & $\mathrm{IC}_{50} 1.32 \mu \mathrm{g} / \mathrm{mL}$ & [22] \\
\hline Lycorine & ornamental plant; Hippeastrum breviflorum & T. vaginalis & cell damage & [23] \\
\hline Lycosinine & ornamental plant; Hippeastrum breviflorum & T. vaginalis & cell damage & [23] \\
\hline Methyl jasmonate & plant hormone & T. vaginalis & cell death & {$[24]$} \\
\hline $\mathrm{N}$-acetyl-L-cysteine & L-cysteine amino acid & T. vaginalis & active in vivo & {$[16]$} \\
\hline Pyrrolocin A & fungal endophyte E6927E & T. vaginalis & $\mathrm{EC}_{50} 60 \mathrm{nM}$ & [25] \\
\hline Quercetin & potatoes; Solanum tuberosum & 3 trichomonads & $18.5-46.6 \%$ & {$[14]$} \\
\hline Resveratrol & grapes; Vitis vinifera & T. vaginalis & $\mathrm{IC}_{50} 25 \mu \mathrm{M}$ & [26] \\
\hline Saponins A, B & medicinal plant; Sapindus saponaria & T. vaginalis & MIC $0.025 \%$; MIC $0.16 \mathrm{mg} / \mathrm{mL}$ & [27] [28] \\
\hline Solanidine & potatoes; Solanum tuberosum & 3 trichomonads & $22.6-48.4 \%$ & [14] \\
\hline a-Solanine & potatoes; Solanum tuberosum & 3 trichomonads & $\mathrm{IC}_{50} 10.9-16.8 \mu \mathrm{M}$ & [14] \\
\hline Tomatidine & tomatoes; Lycopersicon esculentum & 3 trichomonads & $3.2-22.9 \%$ & [29] \\
\hline Tomatine & tomatoes; Lycopersicon esculentum & 3 trichomonads & $\mathrm{IC}_{50} 2.0-7.9 \mu \mathrm{M}$ & [29] \\
\hline Torvosides & medicinal plant; Solanum torvum & T. vaginalis & MIC $6.2-12.5 \mu \mathrm{M}$ & [30] \\
\hline Uliginosin B & medicinal plant; Hypericum polyanthenum & T. vaginalis & cell damage & [11] \\
\hline Ursolic acid & medicinal plant; Manika rufula & T. vaginalis & MIC $25 \mu \mathrm{M}$ & [31] \\
\hline Wogonine & plant leaves; Scutellaria havanensis & T. vaginalis & cytotoxicity & {$[32]$} \\
\hline
\end{tabular}

Bovine, feline, and human trichomonad strains

powders. The two glycoalkaloids completely inhibited all three strains under the test conditions, with the following $\mathrm{IC}_{50}$ values (concentration that inhibited $50 \%$ of the cells under the test conditions) calculated from concentration-response data: for G3, $\alpha$-solanine $15.8 \mu \mathrm{M}$ and $\alpha$-chaconine $35.6 \mu \mathrm{M}$; for $\mathrm{C} 1, \alpha$-solanine $12.6 \mu \mathrm{M}$ and $\alpha$-chaconine $51.5 \mu \mathrm{M}$, and for D1 $\alpha$-solanine $10.9 \mu \mathrm{M}$ and $\alpha$-chaconine $35-60 \mu \mathrm{M}$. Solanidine was less active, inactivating $\mathrm{G} 3, \mathrm{C} 1$ and $\mathrm{D} 1$ to $48.4,22.6$, and $23.0 \%$, respectively. $\mathrm{IC}_{50}$ values were not calculated for inhibitory activities of $<50 \%$. Three potato phenolic compounds also inactivated the three strains. Caffeic acid inhibited G3 to $42.8 \%$; D1 to $43.7 \%$; and $\mathrm{C} 1$ to $21.1 \%$. The corresponding values for chlorogenic acid are $11.4,12.1$, and $21.9 \%$, and for quercetin $45.6,18.9$, and $18.5 \%$, respectively. Additional studies found that six potato peel powders containing glycoalkaloids and other bioactive compounds [44] also inhibited the three trichomonads. The percentage inhibition of G3 ranged from 1 (red potato peel) to 36.6 (organic Russet potato peel); of D1 from 9.0 (red potato peel) to 41.4 (organic Russet potato peel); and of $\mathrm{C} 1$ from 0 (purple potato peel) to 48.6 (organic Russet peel). Disc-diffusion screening revealed no effect on normal microbiota in the vaginal flora.

The cited data indicate that the activities of the potato glycoalkaloids are greater than that of their common aglycone, that the activities of the phenolic compounds are also lower than those of the glycoalkaloids, and that, of the six evaluated peels, the organic Russet potato peels showed the greatest anti-trichomonad activity. 


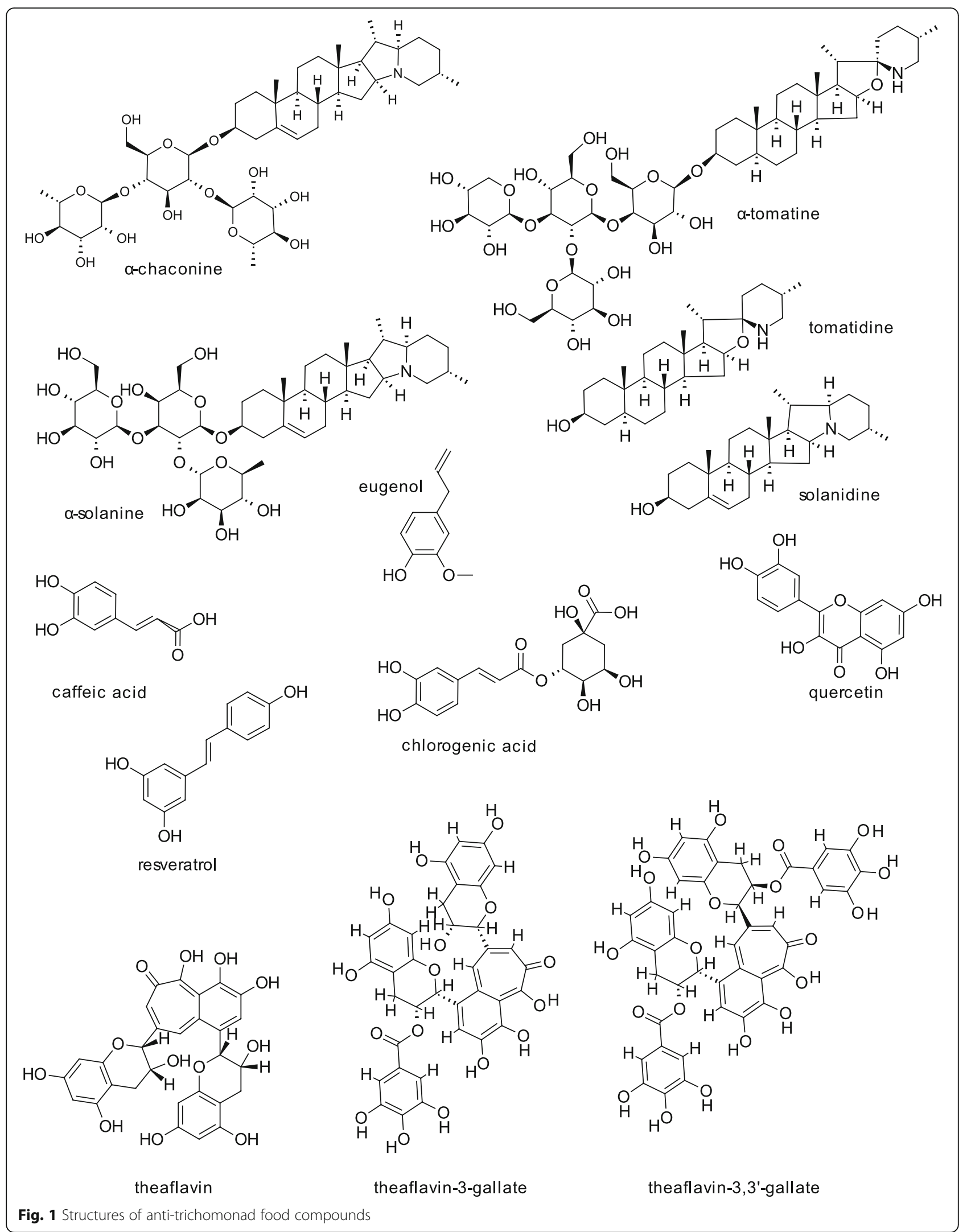


These positive results imply that the test formulations might be able to protect both humans and animals from trichomonad infections. Moreover, in previous studies we reported that the two potato glycoalkaloids inhibited the growth of cancer cells $[45,46]$, and that, compared with the other peel powders, the organic Russet potato peel powder induced the greatest weight loss in mice on a high-fat diet [47], suggesting that the potato glycoalkaloids have multifunctional health properties. Will inexpensive Russet potato peel powders protect humans, farm animals, and cats against cancer, obesity, and trichomoniasis? Will the consumption of baked and boiled potatoes with the peels benefit human health? We are challenged to find answers to these questions.

\section{The tomato glycoalkaloid a-tomatine and the aglycone tomatidine}

Liu, Kanetake [29] reported the following experimental observations on the inactivation of three pathogenic protozoal strains (G3, human $T$. vaginalis; D1, cattle $T$. foetus; and $\mathrm{C} 1$, feline $T$. foetus) by the commercial tetrasaccharide tomato glycoalkaloid tomatine (a 9:1 mixture of $\alpha$-tomatine and dehydrotomatine from tomatoes (Lycopersicon esculentum, Fig. 1) and the aglycone tomatidine lacking the carbohydrate side chain. Under the test conditions, tomatine completely inactivated the three strains, whereas the corresponding inactivation by tomatidine was much lower for all three strains (3.2, 22.9 , and $10.2 \%$, for $\mathrm{G} 3, \mathrm{D} 1$, and $\mathrm{C} 1$, respectively). The calculated $\mathrm{IC}_{50}$ values for tomatine based on doseresponse data of G3, D1, and $\mathrm{C} 1$ are $7.9 \mu \mathrm{M}, 2.7 \mu \mathrm{M}$, and $2.0 \mu \mathrm{M}$, respectively, which compares with $\mathrm{IC}_{50}$ values for metronidazole of $0.72 \mu \mathrm{M}, 0.49 \mu \mathrm{M}$, and $0.55 \mu \mathrm{M}$, respectively (the much lower values indicating inhibition is greater). The results show that the feline trichomonad strain was the most susceptible to inactivation by tomatine. Unlike medicinal antibiotics, tomatine did not affect normal flora bacteria in vitro.

Because the aglycone tomatidine showed lower activity than the glycoside tomatine, it seems likely that the tetrasaccharide side chain is involved in the molecular mechanism of inactivation of the trichomonad cells, possibly by binding to and disrupting the cell membranes, as described by Blankemeyer et al. [48, 49] and de Groot and Müller-Goymann [50]. It would be of interest to find out if inexpensive extracts of green tomatoes and tomato leaves with a high-tomatine content [51, 52] would also be effective against the human, bovine, and feline trichomonads.

Tomatine has also been reported to have other healthpromoting activities, such as reducing plasma cholesterol levels in hamsters [53], and inhibiting the growth of cancer tumors in fish [54], and in mice [55], making it a good target for further investigation in human studies.
Interestingly, tomatine content decreases as the fruit matures on the vine so green, unripe tomatoes can have about 100 times more tomatine than mature red [56], and tomatine is found in processed tomato products including sauce, ketchup, and pickled tomatoes [57]. Jars of high-tomatine pickled green tomatoes are available in some stores.

In related studies Chen, $\mathrm{Li}$ [58] showed that five glycoalkaloids, $\alpha$-chaconine, $\alpha$-tomatine, $\alpha$-solanine, $\alpha$ solamargine, and $\alpha$-solasonine, inhibited the growth of the malaria-causing protozoan Plasmodium yoelii in a 4day study in mice, suggesting that the last two compounds also merit evaluation against $T$. vaginalis and $T$. foetus. Thorne, Clarke [59] reported that $\alpha$-chaconine, $\alpha$-tomatine, and $\alpha$-solasonine inactivated the herpes simplex virus Type I in cell culture, suggesting that these glycoalkaloids might show anti-viral properties against the coronavirus, human immunodeficiency (HIV), and other pathogenic viruses.

\section{Lectin from kidney bean}

Aminou, Alam-Eldin [21] also reported that the biologically active glycoprotein, a lectin from the kidney bean (Phaseolus vulgaris) known to agglutinate (precipitate) cells, induced structural changes in the $T$. vaginalis structure, suggesting that this and other lectins have the potential to act as anti-trichomonad agents. The lectin was also used as a probe against cerebral spinal fluid from patients in an enzyme-linked lectin assay (ELLA) to determine their risk of developing Alzheimer disease [60].

\section{Phytochemical-rich food extracts}

Beverages and foods rich in phytochemicals have also been shown to have inhibitory activity towards trichomonads. For example, using a cell assay, Noritake, Liu [61] determined the inhibitory activities of black tea, green tea, grape, pomegranate, and jujube extracts and dried jujube against $T$. vaginalis $\mathrm{G} 3, T$. foetus $\mathrm{D} 1$, and $T$. foetus $\mathrm{C} 1$. The results show that the black tea extract inactivated the three trichomonads and was most effective against $T$. vaginalis. The extract was also effective against a metronidazole-resistant strain and a cytoadherent strain of $T$. vaginalis. The inhibition correlated with the total extract and individual component [(theaflavin, theaflavin 3-gallate, and theaflavin-3,3' -digallate (Fig. 1)] content of the extracts as determined using HPLC. The black tea extract did not affect normal flora bacteria in vitro.

The inactivation by the catechin-containing green tea and other extracts was variable and lower than that by the black tea extracts. The authors suggest that black tea and its bioactive theaflavin compounds merit further human clinical studies with $T$. vaginalis. Related studies show that individual green tea catechins and black 
theaflavins and tea extracts inhibited the growth of pathogenic bacteria and viruses [62, 63], and multiple human cancer cells [64], and that the theaflavin and catechin content of 77 commercial green and black teas varied widely $[65,66]$, suggesting that clinicians and tea consumers should select teas with the highest content of the bioactive compounds.

Three publications by Sirk et al. [67-69] describe studies on molecular-dynamics computer simulations of green tea catechins and black tea theaflavins and lipid bilayers of cell membranes. The simulations show that the tea compounds have a strong affinity for the lipid bilayer; some are absorbed into the bilayer and some remain on the surface. The molecular structure of the compounds influences their absorption, as well as the ability of their hydroxyl $(\mathrm{OH})$ groups to form hydrogen bonds with the lipid bilayer headgroups. Insight into these molecular events facilitates a better understanding of the mechanism of disruption of cell membranes in biological processes, including the anti-cancer, antibacterial, and antiprotozoal effects.

\section{Plant essential oils and their bioactive compounds}

There have been reports on the anti-trichomonad properties of plant essential oils and compounds isolated from the oils, as illustrated with the following examples. An Australian study by Moon, Wilkinson [70] describes the inhibition of three protozoan pathogens by Lavandula essential oils. Concentrations of $<1 \%$ of L. angustifolia and L. $\times$ intermedia oils completely eliminated the human pathogens T. vaginalis and Giardia duodenalis and the fish pathogen Hex amita inflata. Cheikh-Ali, Adiko [71] reported that the essential oil from rhizomes of Aframomum sceptrum (Zingiberaceace) exhibited remarkable antiprotozoal activity against $T$. vaginalis with an $\mathrm{IC}_{50}$ value of $0.12 \mu \mathrm{L} / \mathrm{mL}$ and a minimum lethal concentration (MLC) value of $1.72 \mu \mathrm{L} / \mathrm{mL}$. The major constituents of the oil determined by gas chromatography/mass spectrometry (GC/MS) analysis are $\beta$-pinene (12.7\%), caryophyllene oxide (10.0\%), and cyperene (6.0\%). The oil also inhibited the growth of Grampositive bacteria. Dai, Peng [18] found that $A$. tsao-ko essential oil used in traditional Chinese medicine to treat stomach disorders and throat infections and its bioactive compound geraniol (Fig. 2), widely used as a fragrance ingredient, were also effective against $T$. vaginalis. The MLC of the oil for one strain of the pathogen was $44.97 \mu \mathrm{g} / \mathrm{mL}$ and the $\mathrm{IC}_{50}$ value, $22.49 \mu \mathrm{g} / \mathrm{mL}$. These values were approximately double with a second protozoal strain. The corresponding value for geraniol, which constitutes $13.69 \%$ of the oil, are $342.96 \mu \mathrm{g} / \mathrm{mL}$ and $171.48 \mu \mathrm{g} / \mathrm{mL}$, respectively. These results show that geraniol showed much lower potency than the oil, suggesting that, in addition to geraniol, some of the 24 compounds identified in the oil by GC-MS must contribute to its potency. Additional studies showed that the oil induced severe morphological changes in the cells. These included partially damaged cytoplasmic membranes, resulting in leakage of cytoplasmic content that presumably led to cell death. Aminou, Alam-Eldin [21] discovered that the oil from the seeds of the Nigella sativa plant (black seed, black cumin spice) native to Egypt induced cell damage with cytoplasmic and nuclear destruction in the ultrastructure of $T$. vaginalis trophozoites, detected by transmission electron microscopy, that is similar to the effect induced by metronidazole, suggesting that the oil might be a useful therapeutic alternative to the synthetic drug. The alcoholic extract was less active than the oil. The authors speculate that the anti-trichomonad effect might be associated with high content of poly-unsaturated linoleic, oleic, and palmitic acids in the oil. Akram Khan and Afzal [72] reported that Nigella sativa seeds contain bioactive alkaloids. Another study by Shaikh, Aaqil [73] describes the use of a molecular docking method that demonstrated that extracts of plant Apamarga Kshara, known to ameliorate cervical erosion in humans, interacted with the amino acid residues of the $T$. vaginalis enzyme carbamate kinase, suggesting that the enzyme might present a biological marker for the inhibition of the trichomoniasis.

Farias, Kato [13] found that essential oils from different Nectandra plant species grown in Brazil contained a variety of compounds, including the phenylpropanoid derivative (+)- $\alpha$-bisabolol (Fig. 2). The oil isolated from the leaves of Nectandra megapotamica contained 93.7\% (+)- $\alpha$-bisabolol. This compound inhibited biofilm formation in methicillin-resistant Staphylococcus aureus and Pseudomonas aeruginosa bacteria and was also active against $T$. vaginalis with an $\mathrm{IC}_{50}$ value of $98.7 \mu \mathrm{g} / \mathrm{mL}$. It also had cytotoxic and hemolytic effects in Vero cells and human erythrocytes. Oliveira, Freitas [74] found that (+)- $\alpha$-bisabolol acted synergistically with the antibiotic drug gentamicin against Escherichia coli. These results suggest the potential value of Nectandra oils and their bioactive compounds in the treatment of infectious diseases caused by clinical and foodborne pathogenic bacteria and by $T$. vaginalis, as well its potential to protect foods against contamination by both microbial and protozoal pathogens.

The fact that essential oils and oil compounds inactivated both pathogenic bacteria and $T$. vaginalis suggest that oils/oil compounds that have been shown to inactivate foodborne microorganisms in vitro and in contaminated food might also be effective against $T$. vaginalis. For example, we reported that 27 of the evaluated 96 essential oils and 12 of the 23 essential oil compounds inactivated multiple species of foodborne pathogenic bacteria (Campylobacter jejuni, E. coli, Listeria monocytogenes, and 

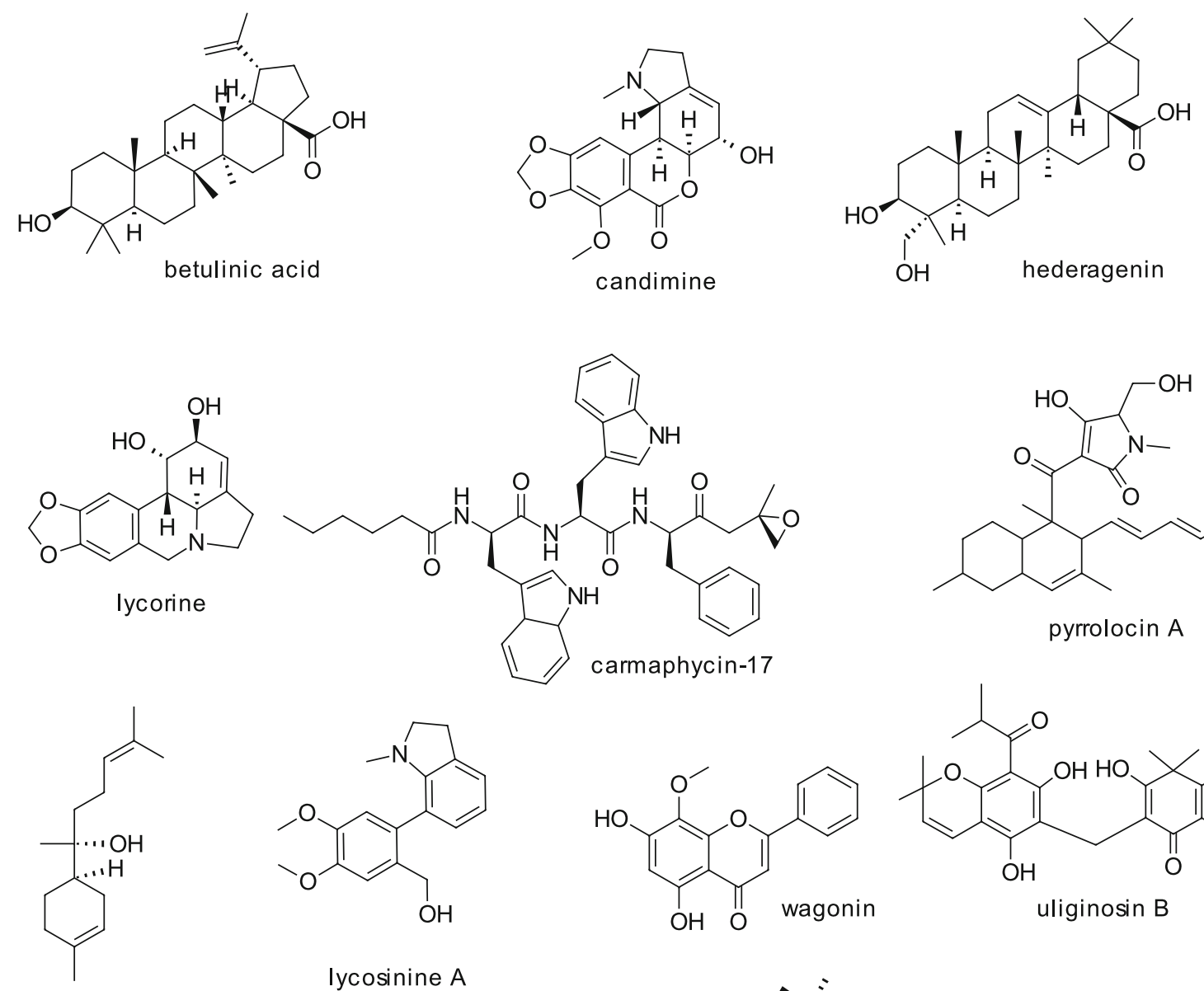<smiles>CCCCCC(=O)NCCC</smiles><smiles>Cc1c[nH]c2ccccc12</smiles><smiles>CC1=CC2=CC3[C@@H](O)C=C(CCN3C1)C2</smiles>

ycorine

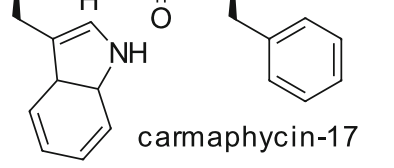<smiles>CC1=CC2CC(C)CCC2C(C)(C(=O)C2=C(O)C(CO)N(C)C2=O)C1/C=C/C=C/CC(C)O</smiles>

pyrrolocin A

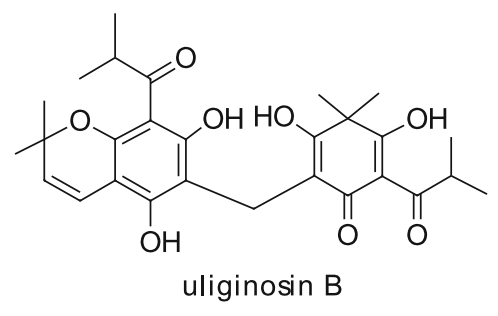

(+)-a-bisabolol lycosinine A

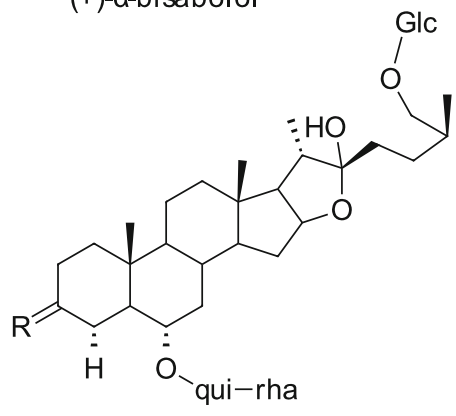

torvoside $A$ : $\mathrm{R}=\mathrm{OH}(\beta-e q), H$ torvoside $\mathrm{H}: \mathrm{R}=\mathrm{O}$

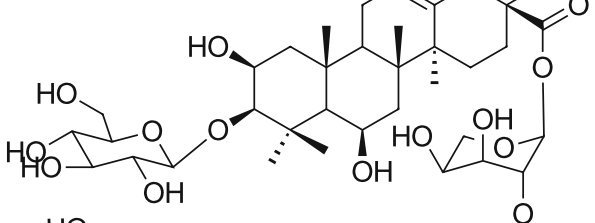
$\mathrm{HO}$<smiles>COc1c(O)cc(O)c2c(=O)cc(-c3ccccc3)oc12</smiles>

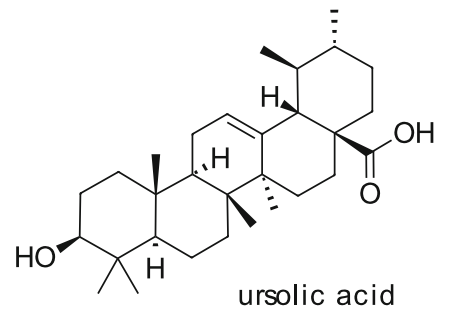<smiles>CC/C=C\C[C@H]1C(=O)CC[C@@H]1CC(=O)OC</smiles><smiles>CCCC(=O)c1c(O)c2c(c(CC3=C(O)[C@@](C)(CC=C(C)C)C(O)=C(C(=O)C(C)C)C3=O)c1O)OC(C)(C)C=C2</smiles>

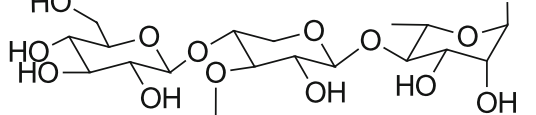
$\mathrm{HO}$ $\mathrm{HO} \quad$ saponin 1 ursolic acid methyl jasmonate<smiles>[R]Oc1cc2c(c(O[R])c1C(=O)C(C)C)C=CC(C)(C)O2</smiles>

benzopyrans

HP1: R1 $=\mathrm{CH}_{3} ; \mathrm{R} 2=\mathrm{CH}_{3}$

HP2: $\mathrm{R} 1=\mathrm{CH}_{3} ; \mathrm{R} 2=\mathrm{H}$

HP3: R1=H; R2= $=\mathrm{CH}_{3}$

Fig. 2 Structures of anti-trichomonad medicinal plant and marine compounds 
Salmonella enterica) in vitro $[75,76]$. Essential oils and oil compounds also inactivated pathogenic bacteria in apple juice [77], ground pork [78], and on leafy greens [79], suggesting that some of the commercially available, foodcompatible essential oils/oil compounds might also inhibit the growth of pathogenic protozoa. Will safe, foodcompatible oils/oil compounds (e.g. allspice, cinnamon, clove, lemongrass, oregano, and thyme essential oils) and their bioactive compounds (e.g. carvacrol, cinnamaldehyde, citral, eugenol, geraniol, thymol) added to liquid and solid foods protect consumers against both microbial infections and trichomoniasis?

\section{Manuka honey}

A study by Sinha, Prakash [80] reported that manuka honey derived from the manuka sexta bees feeding from the manuka tree (Leptospermum scoparium) [81], is known to have anti-microbial and wound-healing properties, inhibited the growth of the pathogenic protozoa Giardia lamblia and $T$. vaginalis with $\mathrm{IC}_{50}$ values of $5.6 \% \mathrm{v} / \mathrm{v}$ and $1.5 \% \mathrm{v} / \mathrm{v}$, respectively, suggesting that the honey has the potential to ameliorate human giardiasis and trichomoniasis. We do not know the bioactive components of the honey that might be responsible for these beneficial properties.

\section{Resveratrol from grapes}

Mallo, Lamas [26] analyzed the in vitro effects of the natural polyphenolic compound resveratrol (Fig. 1) present in grape skins [82], against $T$. vaginalis. The effect was cytostatic at a concentration of $25 \mu \mathrm{M}$ and cytotoxic at $100 \mu \mathrm{M}$, with calculated mean $\mathrm{IC}_{50}$ values of $32 \mu \mathrm{M}$ on day 1 and $25 \mu \mathrm{M}$ on day 2 , respectively. The corresponding $\mathrm{IC}_{50}$ values using metronidazole are $3.2 \mu \mathrm{M}$ and $4.25 \mu \mathrm{M}$, respectively. Although the kinetics of the in vitro inhibition of the $T$. vaginalis cells by resveratrol and metronidazole are similar, in terms of $\mathrm{IC}_{50}$ values, metronidazole was about 6 - to 10 -fold more effective than resveratrol.

The authors also obtained cellular and molecular evidence for the possible mechanism of action of resveratrol against the parasite, as indicated by the following findings. Resveratrol acted primarily as an inhibitor of the enzyme 120-kDA [Fe] hydrogenase (Tvhyd), upregulated the enzyme hydrogenosomal pyruvate-ferrodoxin oxidoreductase, and induced overexpression of the heatshock protein 70 (Hsp 70), a protective protein found in the hydrogenosome of $T$. vaginalis. The authors suggest that the deleterious inhibitory effect of resveratrol resulted from the inhibition of hydrogen production in the hydrogenosomes and changes in iron transport, causing a high degree of bioenergetic stress in the treated parasites. This mechanism differs from the antioxidative mechanisms that have been proposed for other multi- beneficial effects of resveratrol, including cancer [83] and heart disease [84]. Additional studies by several investigators designed to elucidate mechanistic aspect of anti-trichomonad effect in T. vaginalis are highlighted below in a separate Mechanisms section.

\section{Marine compounds}

There have been a few limited studies on effects of marine extracts and isolated compounds on T. vaginalis. A screen by Moo-Puc, Robledo [85] of 25 tropical seaweeds from the Yucatan coast of Mexico showed that $44 \%$ of the extracts had high to moderate activity against T. vaginalis, with Lobophora variegata and Udotea conglutinata species showing the maximal activity with $\mathrm{IC}_{50}$ values of 1.39 and $1.66 \mu \mathrm{g} / \mathrm{mL}$, respectively. CantilloCiau, Moo-Puc [86] reported that an extract from the alga Lobophora variegata from the Yucatan coast of Mexico showed high activity against $T$. vaginalis with an $\mathrm{IC}_{50}$ value of $3.2 \mu \mathrm{g} / \mathrm{mL}$. Several isolated and chemically characterized compounds were less active with an $\mathrm{IC}_{50}$ value of $8.0 \mu \mathrm{g} / \mathrm{mL}$. Scopel, dos Santos [87] found that two marine-associated fungal species (Hypocrea lixii FO2 and Penicillium citrinum F40) isolated from 39 different marine organisms, mainly sponges, from the South Brazilian coast showed up to 100\% growthinhibitory activity against $T$. vaginalis fresh, clinical, and a metronidazole-resistant isolates at a concentration of $2.5 \mathrm{mg} / \mathrm{mL}$. The negative results of a hemolytic assay show that both samples were compatible with red blood cells, suggesting that these samples are potential candidates against $T$. vaginalis. The cited studies suggest that the sea algae, seaweed, fungal and other species could serve as a source of highly active anti-trichomonad formulations.

\section{Medicinal plants: extracts and bioactive compounds Plant extracts and bioactive compounds - in vitro studies}

Here, we briefly outline results from selected reported studies on anti- $T$. vaginalis properties of medicinal plant extracts.

Muelas-Serrano, Nogal [88] reported that, of a large number evaluated American plant extracts, nine were active against Trypanosoma cruzi and Trichomonas vaginalis, with one showing $100 \%$ inhibition of T. vaginalis after exposure for $24 \mathrm{~h}$. A screen by Calzada, YépezMulia [89] of 22 Mexican medicinal plants for antitrichomonal activity against $T$. vaginalis indicated that extracts from Garica papaya and Cocos nucifera had the best activity, with $\mathrm{IC}_{50}$ values of 5.6 and $5.8 \mu \mathrm{g} / \mathrm{mL}$, respectively. All extracts, however, were less active than metronidazole, with an $\mathrm{IC}_{50}$ value of $0.037 \mu \mathrm{g} / \mathrm{mL}$. Five of the evaluated plants are used to treat urogenital tract disorders in Mexican traditional medicine. 
Arthan, Sithiprom [30] investigated the effectiveness of compounds isolated from plants grown in Thailand against $T$. vaginalis. The MICs of several $\beta$-glycosides at $24 \mathrm{~h}$ were in the range of $6.25-12.5 \mu \mathrm{M}$. The glycosides torvosides A and $\mathrm{H}$ (Fig. 2) were more potent than their corresponding deglucosylated torvoside $\mathrm{A}$ and $\mathrm{H}$, whereas other $\beta$-glycosides were generally as active as their corresponding aglycones. Except for dalcochinin, none of the tested compounds showed cytotoxicity against Vero and cancer cell lines (KB and MCF-7). The native Thai plants provide another natural source of anti- $T$. vaginalis compounds.

Fernández-Calienes Valdés, Monzote Fidalgo [32] found that extracts of leaves and stems of Scutellaria havanensis, a plant native to Cuba, and the isolated flavonoid compound wogonin (Fig. 2) exhibited antitrichomonad activity against $T$. vaginalis with the following selectivity indices: methanol extract 7.3 ; chloroform extract 2.8; wogonin 2.0; and metronidazole 322.6. Because antiprotozoal efficacy must have a selectivity index of at least 10, defined as the ratio of concentrations that measures cytotoxic to antiprotozoal activity [90], the authors suggest that the observed activities are probably due to unspecific cytotoxic rather than specific antitrichomonad effects. The test substance also exhibited activity in vitro against Plasmodium berghei parasites, suggesting their possible value against malaria.

Menezes, Rigo [20] evaluated the mechanism of the anti-trichomonad effect of phloroglucinol compounds isolated from a Brazilian Hypericum plant species. The compound isoaustrobrasilol B (Fig. 2) significantly inhibited nucleoside triphosphate diphosphohydrolase (NDPDase) and ecto-5'nucleotidase activities as well as immune changes attributed to extracellular nucleotide accumulation, suggesting that the death of $T$. vaginalis cells and modulation of electonucleotidases induced by the phloroglucinol derivative may increase the susceptibility of the parasite to host immune cells (neutrophils), thus enhancing cell death. A review of the literature of 26 plant types by Ziaei Hezarjaribi, Nadeali [91] indicates that extracts of medicinal herbs such as Artemisia, Zataria multiflora, and Lavandula angustifolia are remarkably effective against $T$. vaginalis, with the most effective Artemisia aucheri extract active at a concentration of $0.1 \mathrm{mg} / \mathrm{mL}$.

Because the activities of plant extracts might be associated with a mixture of bioactive compounds that might act additively, synergistically, or antagonistically, there is a need to isolate and determine activities of the pure compounds, as indicated below for some extracts.

\section{Plant extracts - human studies}

The following studies demonstrate the effectiveness of medicinal plants in alleviating trichomoniasis in women and another study shows the potential of microbiota to increase the therapeutic potential of metronidazole. A randomized study by Moraes, Cunha [92] of the treatment of 60 Brazilian women infected with $T$. vaginalis with $24 \mathrm{mg}$ of the herbal plant Mentha crispa (Lamiaceae family) or $2000 \mathrm{mg}$ of secnidazole (5-nitroimidazole, structurally related to metronidazole) administered orally in tablet form, found that: (a) there was no statistical difference between the two treatments in the observed cure rates, 90 and 96.6\% ( $p=0.621)$, respectively; (b) the adverse effects (mostly nausea, metallic taste) were significantly higher $(p=0.05)$ in the secnidazole $(66.66 \%)$ than in the M. crispa group (20\%), $p=001)$. The cited results show that $M$. crispa seems to offer an alternative and safe treatment for trichomoniasis, and possibly also for giardiasis [93]. It is, therefore, surprising that $M$. crispa has not been adopted for wider clinical evaluation and use in view of its striking beneficial effect at a much lower dose than the synthetic drug.

Abdali, Jahed [94] used a randomized study of 420 women of reproductive age to determine the effect of a vaginal cream containing a medicine made from Zataria multiflora (Labiatae family) against $T$. vaginalis vaginal infections and bacterial vaginosis that often accompanies the protozoal infection. The control group was administered oral metronidazole tablets. The results show that the cream is as effective as the drug in the treatment of bacterial vaginosis $(p=0.01)$ and clinical symptoms associated with $T$. vaginalis $(p=0.001)$. The authors suggest that the cream should also be evaluated for the possible recurrence of $T$. vaginalis following treatment. A study by Sgibnev and Kremleva [95] found that twice daily intravaginal co-administration of $500 \mathrm{mg}$ metronidazole with 1 capsule of the commercial probiotic Gynophilus to 90 women with $T$. vaginalis for 7 days significantly increased the therapeutic potency of the drug (88.6 and 42.9\% for trichomoniasis and 63.6 and $11.9 \%$ for bacterial vaginosis (BV) treated with and without added probiotic, respectively). The binary treatment also decreased the inflammatory response and the $\mathrm{pH}$ and increased the redox potential in the vagina. The authors suggest that these changes are the reason for the increased therapeutic potency. The binary therapy merits further study with some of the described highly active natural anti-trichomonad compounds and extracts. A new vaginal cream containing a mixture of extracts of Eucalyptus camaldulensis leaves, Viola odorata root, and Mentha piperita leaf completely inhibited $T$. vaginalis strain G1 in vitro in the first $24 \mathrm{~h}$, suggesting its potential value for human use [96].

\section{Plant compounds}

Here, we present highlights of reported observations on the anti- $T$. vaginalis properties of selected pure compounds 
isolated from medicinal plants and the use of a murine model to test anti-trichomonad properties in vivo.

\section{Anthraquinones Emodin}

Wang [17] reported that the anthraquinone derivative emodin (1,3,8-trihydroxy-6-methyl-anthraquinone) (Fig. 3) isolated from the root and rhizome of Rheum palmatum inhibited the pathogenicity of $T$. vaginalis in mice. The compound delayed the development of subcutaneous abscesses due to infection by this parasite. It also cured the intravaginal infection of trichomonads through oral administration. In cell cultures, it reduced the cytotoxic effect of the parasite towards mammalian cells. This inhibition was markedly reversed by the coexistence of free radical scavengers, indicating the possible mediation of reactive oxygen species (ROS) in the pathogenicity and inhibition. Other investigators reported that emodin also inhibited breast cancer growth [97], showed antibacterial and antiviral activities when incorporated into model membranes (liposomes) as the vehicle [98], suppressed nonresistant and antibioticresistant pathogenic Staphylococcus aureus bacteria [99], and protected against oxidative damage induced by oxidized fish oil [100], suggesting that the compound has the potential to improve both food safety and human health.

Although Cobo, Eckmann [101] suggest that their murine model of vaginal trichomonad infections is a valuable approach for investigating in vivo pathogenesis and treatment of trichomoniasis, to our knowledge, the above-mentioned study of emodin is the only one that has used mice to determine the efficacy of a natural product. A murine model was also used by Hopper, Yun [102] who reported that the oral administration of the synthetic drug auranofin to mice for 4 days cleared $T$. foetus infection without any apparent side effects. Some of the described highly active natural plant extracts and pure compounds merit further evaluation in mice as a possible intermediate test that might help design and guide clinical evaluations in humans.

\section{Lucidin- $\omega$-isopropyl ether}

Cáceres-Castillo, Pérez-Navarro [22] isolated and characterized the structure of a new anthraquinone (lucidin$\omega$-isopropyl ether) (Fig. 3) from the roots of the plant Morinda panamensis and determined its activity against T. vaginalis. The following methods were used to obtain pure test samples of the anthraquinone. The plant samples were washed under tap water and left to dry inside an oven at $40{ }^{\circ} \mathrm{C}$ for 3 days. The dry material was then ground to a $2-\mathrm{mm}$ mesh diameter. The resulting powders were extracted with methylene chloride in a Soxhlet apparatus, and the concentrated residue was then fractionated on a chromatography column packed with silica gel followed by thin-layer chromatography. Nuclear magnetic resonance spectroscopy (NMR) was used to facilitate assigning the structure of the anthraquinone derivative shown in Fig. 3. The isolated anthraquinone, with an $\mathrm{IC}_{50}$ value of $1.32 \mu \mathrm{g} / \mathrm{mL}$, was found to be similar to efficacy to the metronidazole concentration tested $(6 \mu \mathrm{M}=1.03 \mu \mathrm{g} / \mathrm{mL})$. The compound was also subjected to a series of additional bioassays that showed it was highly selective towards trichomonad trophozoites and was capable of inhibiting their ability to kill HeLa cells and to decrease the proteolytic activity of the proteinase TvMP50 from the trichomonad that was associated with decreased expression of the mp50 gene. The authors suggest that the high trichomonacidal activity of the new anthraquinone merits further action-mode studies to define the mechanism of action.

\section{Structure-activity relationships of anthraquinones}

We evaluated the anti-trichomonad activities of six anthraquinones, the structures of which are shown in Fig. 3, against the three pathogenic protozoal strains G3 (human), C1 (bovine), and D1 (feline) mentioned earlier [103]. The following are the results under the test conditions in terms of percentage inactivation of G3, C1 and D1, respectively: aloe-emodin, 82.3, 99.0, and 92.0; anthraquinone, 62.0, 51.3, and 63.7; anthrarufin, 53.4, 60.0, and 73.4; chrysazin, 56.7; 91.1, and 97.4; emodin, 57.7, 41.4, and 78.8; and purpurin, 58.8, 72.2, and 79.0. These results show that aloe-emodin was the most active compound against the three strains and that structurally different anthraquinones are a major source of new trichomonacidal compounds. In related studies, we have shown that some of the mentioned anthraquinones exhibited antioxidative and anti-inflammatory properties in chemical assays and macrophage cells [104], and that purpurin added to a high-fat diet significantly reduced weight gain in mice [105]. Could purpurin protect individuals against both trichomoniasis and obesity?

\section{Alkaloids - lycorine, lycosinine, and candimine}

The Brazilian investigators Giordani and collaborators demonstrated in a series of studies the potential of extracts of the Amaryllidaceae plant family and their bioactive alkaloids to inhibit the growth of $T$. vaginalis as well as their anti-trichomonad mechanism of action. The following are highlights of some of their findings. The Amaryllidaceae plant family is known for its ornamental value and is also of medicinal interest owing to the occurrence of alkaloids with biological properties. Vieira, Giordani [23] evaluated the anti-T. vaginalis activity of eighteen methylene chloride (dichloromethane) extracts $(12.5$ to $0.19 \mathrm{mg} / \mathrm{mL})$ and isolated six alkaloids (125 to $1.9 \mu \mathrm{g} / \mathrm{mL}$ ) from the Amaryllidaceae species. The alkaloids diminished the viability of the trophozoite stage (from 15 to 40\%). The extracts from Hippeastrum 
<smiles>O=C1c2ccccc2C(=O)c2ccccc21</smiles>

anthraquinone<smiles>O=C1c2cccc(O)c2C(=O)c2c(O)cc(CO)cc21</smiles>

aloe-emodin

(1,8-dihydroxy-3-

hydroxymethylanthraquinone)<smiles>O=C1c2cccc(O)c2C(=O)c2cccc(O)c21</smiles>

chrysazin

(1,8-dihydroxyanthraquinone)<smiles>O=C1c2ccccc2C(=O)c2c(O)c(O)cc(O)c21</smiles>

purpurin

(1,2,4-trihydroxyanthraquinone )<smiles>Cc1cc(O)c2c(c1)C(=O)c1cc(O)cc(O)c1C2=O</smiles>

emodin

\section{(1,3,8-trihydroxy-6-methyl-} anthraquinone)<smiles>O=C1c2cccc(O)c2C(=O)c2cccc(O)c21</smiles>

anthrarufin (1,5-dihydroxyanthraquinone)<smiles>CC(C)OCc1c(O)cc2c(c1O)C(=O)c1ccccc1C2=O</smiles>

lucidin- $\omega$-isopropyl ether

Fig. 3 Structures of plant-derived anti-trichomonad anthraquinones

breviflorum demonstrated the highest anti- $T$. vaginalis activity (viability was reduced by $60 \%$ ). Six fractions from a bioguided study with antiprotozoal activity had lycorine and lycosinine (Fig. 2) as major anti-parasitic components. The higher activity of the extracts when compared with activities of the isolated compounds suggests a synergistic effect of multiple compounds in the extracts. Vieira, Giordani [23] used the following procedure to obtain the extracts and isolated alkaloids. The crude extracts obtained after maceration of fresh bulbs in $96 \%$ ethanol at room temperature for 15 days were acidified with a solution of $10 \% \mathrm{HCl}$. The neutral material was then removed with petroleum ether, the solution was adjusted with $25 \%$ ammonium hydroxide to $\mathrm{pH}$ 
9-10, and then extracted with dichloromethane and $n$-butanol. The alkaloids were then isolated by chromatography and their purity and structures confirmed by high-performance liquid chromatography (HPLC), nuclear magnetic resonance, and mass spectrometric analyses. The described methods offer a useful guide for future efforts designed to obtain pure bioactive compounds from plant sources. Giordani, Weizenmann [15] reported that the Amaryllidaceae alkaloids candimine and lycorine inhibited $T$. vaginalis nucleoside triphosphate diphosphohydrolase and ecto-5'-nucleotidase activities, possibly enhancing the susceptibility of the pathogen to host immune responses. The mechanisms of alkaloidinduced cell death seems to involve the arrest of the cell cycle by a pathway that does not involve criteria that are associated with apoptosis or apoptosis-like death [106].

To clarify the mechanism of cell death further, Giordani, Junior [107] evaluated the anti-trichomonad activity of lycorine and six aliphatic and aromatic esters at concentrations of $125 \mu \mathrm{M}$ and $250 \mu \mathrm{M}$. About $60 \%$ of the parasites remained viable after exposure for $24 \mathrm{~h}$ to both concentrations of lycorine. By contrast, with the lauroyl ester, the observed reduction was to 16 and $3 \%$ residual activity at the two concentrations, respectively, suggesting that the lipophilicity of the fatty acid ester associated with the lauroyl side chain might facilitate its penetration through the amitochondriated layer of the parasite, resulting in enhanced cytotoxicity. The authors also suggest the data imply that: (a) the free (unprotected) $\mathrm{OH}$ groups at the $\mathrm{C}-1$ and $\mathrm{C}-2$ position of the lycorine molecule are not involved in the antiparasitic activity; and (b) esterification of lycorine with other lipophilic fatty acids at one or both $\mathrm{OH}$ groups has the potential to improve the inhibition of $T$. vaginalis. A related study found that besides having anti- $T$. vaginalis activity, lycorine modulates ectonucleotidases and stimulates neutrophils to secrete reactive oxygen species (ROS), suggesting that this mechanism of action exerted by the alkaloid could enhance the susceptibility of $T$. vaginalis to host immune cells, contributing to protozoan clearance [108].

These results demonstrate the antiprotozoal potential of the multiple bioactive compounds in the Amaryllidaceae plant species against $T$. vaginalis.

\section{Benzopyran HP1 and Uliginosin B}

Cargnin, Vieira [11] found that uliginosin B and three benzopyrans (Fig. 2) isolated from Hypericum polyanthenum, a Brazilian native plant, had anti-T-vaginalis activity that was associated with damage to the cell membrane (> 90\% release of lactic dehydrogenase, LDH). Benzopyran HP1 had the best activity against both susceptible and metronidazole-resistant clinical isolates (TV-LACM2), with no cytotoxicity towards mammalian cells. The authors suggest that benzopyran HP1 with significant antiprotozoal activity and selectivity seems to be a promising candidate for further study.

\section{Hedargenin}

A review (meta-analysis) by Mehriardestani, Aliahmadi [19] that discusses reported anti-trichomonad effects of 13 medicinal plants and some of their bioactive purified compounds identified 95 relevant in vitro and clinical studies, including human studies. Alkaloids, isoflavonoid glycosides, essential oils, lipids, saponins, and sequiterpene lactones isolated from a number of medicinal plant families were shown to possess anti-trichomonad activity. These include cardimine, lycorine, methyl jasmonate and 12 other compounds with defined structures that exhibited 'remarkable' anti-trichomonad properties. The pentacyclic terpenoid hedargenin (Fig. 2) from the bark of Cassnia holstii had the best activity, with an $\mathrm{IC}_{50}$ value against $T$. vaginalis of $2.8 \mu \mathrm{M}$. The fact the structures of the alkaloids lycorine, lycosinine, berberine, and lirodenin contain the 1,3 benzodioxole ring system suggests that this functional group might be involved in the inhibitory mechanism and other reported bioactivities.

\section{Methyl jasmonate}

Because mitochondria are target organelles of jasmonates, plant lipids that act as stress phytohormones that help protect plants against stress conditions such as drought and phytopathogens, Ofer, Gold [24] wanted to find out if methyl jasmonate (Fig. 2) would induce cell death in the amitochondriate T. vaginalis (lacking mitochondria). They found that cell death did occur following exposure of the parasite to methyl jasmonate and was associated with an apoptotic-like mechanism without the apparent DNA laddering sub G (1) cell cycle stage peak and caspase-3-activation, similar to the effect observed with metronidazole. Additional studies showed that methyl jasmonate was also cytotoxic to a metronidazole-resistant strain of $T$. vaginalis (ATCC 50143). The authors suggest that the mitochondriaindependent cytotoxicity of methyl jasmonate could enable it to serve as a potential new agent against trichomoniasis. Vilela, Menna-Barreto [109] confirmed, using flow cytometry and scanning and transmission electron microscopy, that methyl jasmonate induced cell death and loss of hydrogenosomal membrane potential in $T$. vaginalis.

Gunjegaonkar and Shanmugarajan [110] note that the antioxidant and antimicrobial properties of methyl jasmonate are the basis for its use as a food preservative and that its anti-inflammatory properties provide a rationale for clinical applications. The above-mentioned results with $T$. vaginalis indicate this could include the treatment of trichomoniasis. Potentially other plant stress hormones and bioactive compounds, including 
auxins, gibberellins, cytokinins, abscisic acid, salicylic acid, brassinosteroids, and strigolactones that are synthesized within specialized plant cells, could exhibit antitrichomonad properties.

\section{Betulinic and ursolic acids and derivatives}

Innocente, de Brum Vieira [12] found that betulinic and ursolic acids (Fig. 2) and the piperazine derivative of betulinic acid inhibited the growth of $T$. vaginalis. The derivative showed greater activity than the parent compound. Vieira, Silva [111] found that Manika rufula plants from the Caatinga desert region of Brazil contained a number of characterized compounds that inhibited T. vaginalis. These included the $\alpha$-amyrin caproate, $\beta$-amyrin caproate, lupeol acetate, and ursolic acid. After incubation for $2 \mathrm{~h}$, ursolic acid reduced about $98 \%$ of parasite viability and induced drastic ultrastructural alterations in the cells, as observed by scanning electron microscopy. Bitencourt, de Brum Vieira [31] reported that the triterpene compound ursolic acid and its derivative, 3-oxime-urs-12-en-28-oic-ursolic acid, were active against fresh clinical isolates of $T$. vaginalis with an MIC of $25 \mu \mathrm{M}$. The derivative also inhibited a metronidazoleresistant $T$. vaginalis isolate and was not active in a hemolysis assay or cytotoxic to Vero cells, suggesting its value as potential trichomonocidal agent. Hübner, de Brum Vieira [112] also found that derivatives of betulinic acid inactivated $T$. vaginalis.

\section{Saponins}

Rocha, de Brum Vieira [27] found that saponins (glycosylated triterpenes) isolated from Quillaja, Passiflora, and Ilex plant species had high anti- $T$. vaginalis activity with an MIC of $0.025 \%$. All samples induced erythrocyte lysis and release of LDH. An evaluation by Damke, Tsuzuki [28] of purified saponins of the medicinal plant of Sapindus saponaria, used traditionally to cure ulcers, external wounds, and inflammation revealed their inhibitory potency against $T$. vaginalis with an MIC value of $0.156 \mathrm{mg} /$ $\mathrm{mL}$ for nonclinical strains and $0.078 \mathrm{mg} / \mathrm{mL}$ for a clinical strain. Jain, Kumar [113] reported on a related study on the potential value of Sapindus saponaria trichomonocidal saponins for prophylactic contraception.

An uncommon saponin (saponin 1, Fig. 2) isolated by de Brum Vieira, Silva [114] from the Brazilian medicinal plant Manilkara rufula (Sapotaceae family) also known as 'macarunduba' inactivated $T$. vaginalis in vitro without toxicity against the human vaginal HMVII cells, suggesting that the compound does not affect host cells. Additional studies of mechanistic interest show that the compound reduced the cytoadherence of the pathogen to host cells, did not affect ROS production by neutrophils, did not hemolyse erythrocites, and disrupted the cell membrane of the pathogen. The authors suggest that the trichomonocidal effect against $T$. vaginalis is due to profound cell membrane damage.

Saponins are another class of natural compounds that merit further study for their anti-trichomonad properties in rodents and humans. de Groot and Müller-Goymann [50] confirmed that saponins such as digitonin and tomatine interact strongly with model membranes as well as natural membranes of erythrocytes, suggesting that their anti-trichomonad effect might involve disruption of the $T$. vaginalis cell membrane.

\section{Fungal compounds - pyrrolocin a}

Patridge, Darnell [115] found that the bioactive 3decalinoyltetramic acid (pyrrolocin A) (Fig. 2) they isolated from the Amazonian fungal endophyte E6927E inhibited the growth of the pathogenic bacteria Staphylococcus aureus and Enterococcus faecalis as well as isolates of the pathogenic fungal strains Candidas albicans and Aspergillus sp. King, Carter [25], using an image-based, high-throughput, and high-content for testing natural products for anti-trichomonal activity, discovered that pyrrolocin A was also a potent inhibitor of $T$. vaginalis with an effective inhibitory concentration $\left(\mathrm{EC}_{50}\right)$ of $60 \mathrm{nM}$. Because the fungal compound also showed limited toxicity towards mammalian cervical cells with a high selectivity index of $>100$, the results of the two investigations suggest that pyrrolocin A has the potential to protect food and humans concurrently against contamination and infection by pathogenic bacteria, fungi, and T. vaginalis. Will pyrrolocin A, with the exceptional high in vitro activity against $T$. vaginalis, also show similar activity after oral consumption or intravaginal application in women? Will pyrrolocin Asupplemented liquid and solid food protect humans against microbial, fungal, and protozoal infections? Will pyrrolocin $\mathrm{A}$ also be active against antibiotic-resistant bacteria, fungi $[116,117]$ and protozoa in vitro and in vivo? We are challenged to respond to these research needs. (Also see the above section on marine compounds for a description of anti-trichomonal effects of compounds from marine fungi).

\section{Photodynamic therapy}

Two investigations describe photodynamic treatment as a potential new anti-trichomonad therapy. da Silva, Ribeiro Cde [118] found that exposure of $T$. foetus protozoa to light sensitized with an aluminum phthalocyanine tetrasulfonated photosensitizer efficiently killed the bovine pathogen. The associated morphological changes in the cells included membrane projections, nucleus fragmentation, endoplasmic reticulum proliferation, and cytoplasmic vacuolization, suggesting the possible value of the treatment for bovine trichomoniasis. Silva Fonseca, Alacoque [119] exposed metronidazole sensitive 
and resistant $T$. vaginalis strains to methylene blue as the light-emitting diode (LED). They found that light alone was ineffective, but the sensitized light inhibited up to $81 \%$ of the nonresistant and $91.1 \%$ of the resistant strains, respectively. The authors suggest that the effective photodynamic therapy offers great potential for routine use in women with trichomoniasis.

\section{Mechanisms of anti-trichomonad effects}

In addition to mechanistic aspects mentioned above, here we briefly outline additional efforts that help clarify the anti-trichomonad mechanisms that are applicable to different classes of compounds.

Dirkx, Boyer [120] found that T. vaginalis has the gene-coding capacity to produce the enzyme betafructofuranosidase that is capable of hydrolyzing di- and tri-saccharides such as sucrose containing a terminal non-reducing fructose residue, suggesting that the inability of sucrose to support the growth of $T$. vaginalis is not due to the lack of an enzyme that can degrade (catabolize) the disaccharide. Puente-Rivera, Villalpando [121] characterized the previously identified $50 \mathrm{kDa}$ metalloproteinase aminopeptidase P member TvMP50 as a new zinc-ion-mediated parasite virulence factor. These observations and additional studies suggest that the presence of TvMP50 during male trichomoniasis might explain the survival of $T$. vaginalis within the adverse conditions of the male urogenital microenvironment. In a follow-up study, Arreola, Villalpando [122] reported that the TvMP50 metalloproteinase is a monomeric aminopeptidase P-like enzyme. Will inhibition of the virulence enzyme protect males against trichomoniasis? O'Donoghue, Bibo-Verdugo [16] showed that clinically approved cancer drugs that inhibit the proteasome also have high activity in the enriched $T$. vaginalis in cell-free assays. The proteasome inhibitor carmaphycin-17 (Fig. 2) derived from the marine natural product carmaphycin showed greater activity against $T$. vaginalis than the reference drug metronidazole, as well as the ability to overcome metronidazole resistance. The authors suggest that these observations and additional mechanistic studies validate the proteasome of $T$. vaginalis as a therapeutic target for the development of a novel class of trichomonacidal agents. Quan, Kang [123] found that cervical epithelium cells exposed to $T$. vaginalis for $4 \mathrm{~h}$ produced intracellular and mitochondrial ROS in a parasite-load-dependent manner and that subsequent treatment with the ROS scavenger $\mathrm{N}$ acetyl-L-cysteine $\quad\left[\mathrm{CH}_{2}(\mathrm{SH})-\mathrm{CH} \quad\left(\mathrm{NHCOCH}_{3}\right)-\mathrm{COOH}\right.$, $\mathrm{NAC}]$ reversed the effect on apoptosis and NF- $\kappa \mathrm{B}$ inactivation of the cells. Another example is the observation by Sharma, Kumar [124] that a synthetic thiol compound eliminated $T$. vaginalis more efficiently than metronidazole via sulfhydryl-disulfide interchange reactions. The authors suggest that this represents a proof of concept for the selective targeting of Trichomonas. This proof of concept is supported by our observation that modification of disulfide bonds of the enzyme that inhibits trypsin in soy flour by cysteine $\left[\left(\mathrm{CH}_{2}(\mathrm{SH})-\mathrm{CH}\left(\mathrm{NH}_{2}\right)-\mathrm{COOH}\right]\right.$ and NAC through formation of mixed disulfides resulted in loss of inhibitory activity and in increased digestibility and nutritional value in rats [125]. Possible molecular mechanisms for these events might involve the initial reaction of the added sulfhydryl (thiol) compound ( $\mathrm{R}-\mathrm{SH}$ - cysteine, NAC, etc.) with a trichomonas protein disulfide bond (P-S-S-P) to form R-SS-P (a mixed disulfide) + P-SH (disulfide-reduced protein). These transformations could produce biologically inactive trichomonad proteins with mixed and rearranged disulfide bonds [126] that might be responsible for the loss of pathogenicity. These observations imply that $\mathrm{SH}$-antioxidants can protect cells against oxidative damage by $T$. vaginalis. Because antioxidative amino acid cysteine $\left[\left(\mathrm{CH}_{2}(\mathrm{SH})-\mathrm{CH}\right.\right.$ $\left.\left(\mathrm{NH}_{2}\right)-\mathrm{COOH}\right]$ and the cysteine derivative NAC also protected frog embryos against adverse effects of acrylamide $[127,128]$, will cysteine, NAC, and the tripeptide glutathione, and other antioxidative (anti-free radical) sulfhydryl (SH)-containing compounds also protect human and animal tissues against adverse effects induced by ROS [129] produced by $T$. vaginalis and $T$. foetus?

The results from two related studies show major differences in the content and metabolism of sulfur and other amino acids in the two trichomonad species. Nozaki, Ali [130] reported that the metabolism of sulfur amino acids in $T$. vaginalis probably influences their virulence and defense against stress. Based on an extensive bioanalytical study, Westrop, Wang [131] showed that there are major differences in cysteine and methionine synthesis and metabolism in $T$. vaginalis and $T$. foetus, that both trichomonads synthesize methylthioadenosine by an unusual mechanism, that $T$. foetus has higher levels of ornithine and citrulline than $T$. vaginalis and released high levels of the polyamine putrescine, and that $T$. vaginalis but not $T$. foetus exported 2hydroxyisocaproic acid derived from leucine. Because these biochemical events and associated enzymes probably contribute to the viability of the protozoa, inhibition of the active sites of the enzymes might transform pathogenic to nonpathogenic trichomonads.

On the basis of the observed inhibition of both T. vaginalis and $T$. foetus by synthetic diamine compounds and its reversal by the natural putrescine, Rigo, Trein [132] suggest that their mechanism of action might be via the polyamine pathway that is distinct from that observed with metronidazole. These results imply that diamines have the potential to reduce the in vivo pathogenicity of the two trichomonads.

A detailed study by Bradic, Warring [133] using highthroughput methods for large-scale genetic comparison of many strains of resistant and sensitive isolates of $T$. 
vaginalis was used to identify a panel of biomarkers associated with resistance that can be used as a diagnostic tool. Will these biomarkers help guide studies designed to overcome resistance?

The cited studies indicate the complexity of the antitrichomonad mechanisms, where structurally different natural and synthetic compounds seem to act on metabolic pathways of the protozoa that are similar to or different from those observed with metronidazole. Which mechanistic inactivation pathway of anti-trichomonad compounds will be effective against both susceptible and metronidazole-resistant protozoa strains in vivo?

\section{Safety/toxicity aspects of anti-trichomonad compounds}

We do not know if an anti-trichomonad compound that is effective in cell assays might also be effective in farm and domestic animals and in humans. The present study indicates that most of the anti-trichomonad compounds listed in Table 1 have not been evaluated for their efficacy in vivo. A major objective of the present review is to motivate clinicians and veterinarians to evaluate the therapeutic potential of the most active compounds listed in the table against trichomonad strains that infect humans and animals and described extracts containing multiple bioactive compounds. Such studies should include determination of the ratio the effective to toxic dose levels. The higher the ratio, the safer the compound.

Here, we will also briefly mention highlights on the safety of selected anti-trichomonads listed in Table 1. As mentioned earlier, the higher the value of the selectivity index (SI) of an anti-trichomonad in cell assays, the greater the safety. Cargnin, Vieira [11] reported a high SI for the anti-trichomonad benzopyran HP1 and a low one for uliginosin B. A summary of the widely studied safety of the anti-trichomonad potato glycoalkaloids $\alpha$ chaconine and $\alpha$-solanine by Elkahoui, Bartley [47] notes that because high levels of these compounds are reported to induce adverse effects in some cells as well as in vivo, it seems prudent to include safety assessment in any future in vivo studies. Kim, Nam [55] found no apparent adverse effects in mice consuming diets supplemented with the anti-trichomonad tomato glycoalkaloid tomatine. Some individuals consume high-tomatine pickled green tomatoes with no apparent adverse effects [134]. The anti-trichomonad caffeic and chlorogenic acids and quercetin from potatoes and resveratrol from grapes are widely consumed safe food ingredients. The use of probiotics in the treatment of trichomoniasis in women seems to reduce the adverse effects of metronidazole [95]. Finally, Zhao, Lu [135] reported that because the anti-trichomonad emodin prolonged the lifespan of the invertebrate animal Caenorhabditis elegans, this apparently safe compound might serve as an anti-aging dietary supplement.

\section{Conclusions}

The worldwide use of herbal medicines is increasing, although without the apparent adequate education of physicians and consumers about their efficacy and safety [136]. It is therefore not surprising that plants and their extracts have become the focus of studies on their activity against pathogenic protozoa such as T. vaginalis. The results of the studies cited here describe the potential of food, marine, and medicinal plant extracts and isolated pure compounds to inhibit the growth of $T$. vaginalis parasitic strains that cause the sexually transmitted disease trichomoniasis in humans and the inhibition of the related T. foetus strains that infect farm and domestic animals. The studies indicate that some of the natural plant extracts and bioactive compounds are highly active against these parasites, suggesting that they might be able to fully or partially replace the widely used drug metronidazole, especially against resistant trichomonad strains.

Highly active formulations include potato and tomato glycoalkaloids, black tea extracts, and several essential oils and plant and marine extracts. There is also progress in the therapy to expose the protozoa to photosensitized light. It would be of interest to compare the therapeutic efficacy of treatment by light with some of the anti-trichomonad formulations derived from natural sources. This is, however, still a challenging problem because only a few studies have reported on medicinal plants that have a similar efficacy against $T$. vaginalis in infected women to that observed with metronidazole. One of the plants, Zataria multiflora, had a dual benefit: it inhibited both $T$. vaginalis and inactivated pathogenic bacteria in the vagina that cause vaginosis, which often accompanies trichomoniasis. There is, therefore, an urgent need to evaluate some of the other antitrichomonad formulations based on effective natural and safe compounds and extracts in human trials for their efficacy against both trichomoniasis and vaginosis, as well as their efficacy in infected cows, bulls, pigs, cats, and dogs. Some of these compounds could be used in conjunction with probiotics to restore or modify the natural microbiota of the urogenital environment. We hope and anticipate that this review will stimulate interest in such studies, in view of the fact that several of described anti-trichomonad compounds have been reported to have additional health-promoting properties, including anti-oxidative, anti-inflammatory, anti-acrylamide, antiobesity, anti-carcinogenic, anti-microbial, anti-viral, antimalarial, and anti-aging effects. As noted above, the use of the described extracts and isolated pure compounds in the prevention and treatment of trichomoniasis and other diseases should be guided by the ratio of preventive/therapeutic to toxic dose. A combination of low doses of metronidazole with the active extracts and 
isolated compounds might act synergistically with reduced side effects to benefit human health.

Finally, the need for new treatments is strikingly illustrated by the report from the National Institute of Allergy and Infectious Diseases, National Institute of Health (NIH) [5] that notes the need for new therapeutics to help overcome the global epidemic of sexually transmitted infections, including trichomoniasis, chlamydia, gonorrhea, and syphilis. Will the anti-trichomonad compounds and extracts described in the present study also inhibit pathogens that cause chlamydia, gonorrhea, syphilis, the coronavirus and the human immunodeficiency (HIV) virus?

\section{Abbreviations}

BV: Bacterial vaginosis; CSTs: Microbiota states or community types; $\mathrm{EC}_{50}$ : Effective concentration that inactivates (inhibits, eliminates, kills) 50\% of the cells under the test conditions; GC-M: Gas chromatography-mass spectrometry; HIV: Human immunodeficiency virus; $I \mathrm{C}_{50}$ : Concentration that inhibits $50 \%$ of the cells under the test conditions; IL-6: Interleukin 6; LDH: Lactic dehydrogenase; LED: Light-emitting diode; HPLC-PAD: highperformance liquid chromatography with pulsed amperometric detection; MIC: Minimum inhibitory concentration; MLC: Minimum lethal concentration; ROS: Reactive oxygen species; STD: Sexually transmitted disease; TNFa: Tumor necrosis factor-a

\section{Acknowledgements}

We thank Carol E. Levin for constructive comments and for creating the three structural figures as well as colleagues whose names are mentioned in the cited references for excellent scientific collaboration.

\section{Authors' contributions}

MF and KML conceived the need for a comprehensive review that integrates our results on anti-trichomonad food compounds and extracts with those by other investigators on anti-trichomonad plant, marine, and fungal compounds and extracts. MF, CCT, LWC, and KML contributed to the writing of this manuscript and approved the final draft.

\section{Funding}

Not applicable.

Availability of data and materials

Not applicable.

Ethics approval and consent to participate

Not applicable.

\section{Consent for publication}

Not applicable.

\section{Competing interests}

The authors declare that they have no competing interests.

\section{Author details}

${ }^{1}$ United States Department of Agriculture, Healthy Processed Foods Research Unit, Agricultural Research Service, Albany, CA 94710, USA. ²United States Department of Agriculture, Foodborne Toxins Detection and Prevention Research Unit, Agricultural Research Service, Albany, California 94710, USA. ${ }^{3}$ Department of Biological Sciences, University of the Pacific, Stockton, CA 95211, USA.

Received: 3 February 2020 Accepted: 25 August 2020

Published online: 09 September 2020

\section{References}

1. Beers MH. The Merck manual of diagnosis and therapy. 18th ed. Whitehouse Station, NJ: Merck Research Laboratories; 2006.
2. World Health Organization - Dept. of Reproductive Health and Research Global incidence and prevalence of selected curable sexually transmitted infections - 2008. Geneva: WHO; 2012. p. 20.

3. Rowley J, Vander Hoorn S, Korenromp E, Low N, Unemo M, Abu-Raddad LJ, et al. Chlamydia, gonorrhoea, trichomoniasis and syphilis: global prevalence and incidence estimates, 2016. Bull World Health Organ. 2019;97(8):548-62P.

4. Stemmer SM, Mordechai E, Adelson ME, Gygax SE, Hilbert DW. Trichomonas vaginalis is most frequently detected in women at the age of peri -/premenopause: an unusual pattern for a sexually transmitted pathogen. Am J Obstet Gynecol. 2018;218(3):328.e1-e13.

5. Eisinger RW, Erbelding E, Fauci AS. Refocusing research on sexually transmitted infections. J Infect Dis. 2019:jiz442. https://doi.org/10.1093/ infdis/jiz442.

6. Givens MD. Review: risks of disease transmission through semen in cattle. Animal Int J Animal Bioscie. 2018;12(s1):s165-s71.

7. Morin-Adeline V, Mueller K, Conesa A, Šlapeta J. Comparative RNA-seq analysis of the Tritrichomonas foetus PIG30/1 isolate from pigs reveals close association with Tritrichomonas foetus BP-4 isolate 'bovine genotype'. Vet Parasitol. 2015;212(3-4):111-7.

8. Gookin JL, Hanrahan K, Levy MG. The conundrum of feline Trichomonosis. J Feline Med Surg. 2017;19(3):261-74

9. Paul A, Stayt J. The intestinal microbiome in dogs and cats with diarrhoea as detected by a faecal polymerase chain reaction-based panel in Perth, Western Australia. Aust Vet J. 2019;97(10):418-21.

10. Bastos BF. Almeida FMd, Brener B. what is known about Tritrichomonas foetus infection in cats? Rev Bras Parasitol Vet. 2019;28(1):1-11.

11. Cargnin ST, PdB V, Cibulski S, Cassel E, RMF V, Montanha J, et al. antiTrichomonas vaginalis activity of Hypericum polyanthemum extract obtained by supercritical fluid extraction and isolated compounds. Parasitol Int. 2013; 62(2):112-7.

12. Innocente AM, de Brum VP, Frasson AP, Casanova BB, Gosmann G, Gnoatto $\mathrm{SCB}$, et al. Anti-Trichomonas vaginalis activity from triterpenoid derivatives. Parasitol Res. 2014;113(8):2933-40.

13. Farias KS, Kato NN, Boaretto AG, Weber Jl, Brust FR, Alves FM, et al. Nectandra as a renewable source for (+)-a-bisabolol, an antibiofilm and anti-Trichomonas vaginalis compound. Fitoterapia. 2019:136:104179.

14. Friedman M, Huang V, Quiambao Q, Noritake S, Liu J, Kwon O, et al. Potato peels and their bioactive glycoalkaloids and phenolic compounds inhibit the growth of pathogenic trichomonads. J Agric Food Chem. 2018;66(30):7942-7.

15. Giordani RB, Weizenmann M, Rosemberg DB, De Carli GA, Bogo MR Zuanazzi JAS, et al. Trichomonas vaginalis nucleoside triphosphate diphosphohydrolase and ecto-5'-nucleotidase activities are inhibited by lycorine and candimine. Parasitol Int. 2010;59(2):226-31.

16. O'Donoghue AJ, Bibo-Verdugo B, Miyamoto Y, Wang SC, Yang JZ, Zuill DE, et al. 20 S proteasome as a drug target in Trichomonas vaginalis. Antimicrob Agents Chemother. 2019;63(11):e00448-19.

17. Wang $\mathrm{H}-\mathrm{H}$. Antitrichomonal action of emodin in mice. J Ethnopharmacol. 1993:40(2):111-6.

18. Dai M, Peng C, Peng F, Xie C, Wang P, Sun F. Anti-Trichomonas vaginalis properties of the oil of Amomum tsao-ko and its major component, geraniol. Pharm Biol. 2016;54(3):445-50.

19. Mehriardestani M, Aliahmadi A, Toliat T, Rahimi R. Medicinal plants and their isolated compounds showing anti-Trichomonas vaginalis- activity. Biomed Pharmacother. 2017:88:885-93.

20. Menezes CB, Rigo GV, Bridi H, DdS T, Macedo AJ, von Poser GL, et al. the anti-Trichomonas vaginalis phloroglucinol derivative isoaustrobrasilol $B$ modulates extracellular nucleotide hydrolysis. Chem Biol Drug Des. 2017; 90(5):811-9.

21. Aminou HA, Alam-Eldin $\mathrm{YH}$, Hashem HA. Effect of Nigella sativa alcoholic extract and oil, as well as Phaseolus vulgaris (kidney bean) lectin on the ultrastructure of Trichomonas vaginalis trophozoites. J Parasit Dis. 2016;40(3): 707-13.

22. Cáceres-Castillo D, Pérez-Navarro Y, Torres-Romero JC, Mirón-López G, Ceballos-Cruz J, Arana-Argáez V, et al. Trichomonicidal activity of a new anthraquinone isolated from the roots of Morinda panamensis seem. Drug Dev Res. 2019;80(1):155-61.

23. Vieira PB, Giordani RB, De Carli GA, Zuanazzi JA, Tasca T. Screening and bioguided fractionation of Amaryllidaceae species with anti-Trichomonas vaginalis activity. Planta Med. 2011;77(10):1054-9. 
24. Ofer K, Gold D, Flescher E. Methyl jasmonate induces cell cycle block and cell death in the amitochondriate parasite Trichomonas vaginalis. Int J Parasitol. 2008;38(8):959-68.

25. King JB, Carter AC, Dai W, Lee JW, Kil Y-S, Du L, et al. Design and application of a high-throughput, high-content screening system for natural product inhibitors of the human parasite Trichomonas vaginalis. ACS Infect Dis. 2019; 5(8):1456-70.

26. Mallo N, Lamas J, Leiro JM. Hydrogenosome metabolism is the key target for antiparasitic activity of resveratrol against Trichomonas vaginalis. Antimicrob Agents Chemother. 2013;57(6):2476-84.

27. Rocha TD, de Brum VP, Gnoatto SCB, Tasca T, Gosmann G. Anti-Trichomonas vaginalis activity of saponins from Quillaja, Passiflora, and Ilex species. Parasitol Res. 2012;110(6):2551-6.

28. Damke E, Tsuzuki JK, Chassot F, Cortez DAG, Ferreira ICP, Mesquita CSS, et al. Spermicidal and anti-Trichomonas vaginalis activity of Brazilian Sapindus saponaria. BMC Complement Altern Med. 2013;13(1):196.

29. Liu J, Kanetake S, Wu Y-H, Tam C, Cheng LW, Land KM, et al. Anti-protozoal effects of the tomato tetrasaccharide glycoalkaloid tomatine and the aglycone tomatidine on mucosal trichomonads. J Agric Food Chem. 2016; 64(46):8806-10.

30. Arthan D, Sithiprom S, Thima K, Limmatvatirat C, ChavalitshewinkoonPetmitr P, Svasti J. Inhibitory effects of Thai plants $\beta$-glycosides on Trichomonas vaginalis. Parasitol Res. 2008;103(2):443-8.

31. Bitencourt FG, de Brum VP, Meirelles LC, Rigo GV, da Silva EF, Gnoatto SCB, et al. Anti-Trichomonas vaginalis activity of ursolic acid derivative: a promising alternative. Parasitol Res. 2018;117(5):1573-80.

32. Fernández-Calienes Valdés A, Monzote Fidalgo L, Sariego Ramos I, Marrero Delange D, Morales Rico CL, Mendiola Martínez J, et al. Antiprotozoal screening of the Cuban native plant Scutellaria havanensis. Pharm Biol. 2016; 54(12):3197-202

33. Tam CC, Land KM, Cheng LW. Prebiotics, probiotics, and bacterial infections [Online First: https://www.intechopen.com/online-first/prebiotics-probioticsand-bacterial-infections]. Prebiotics and Probiotics - Potential Benefits in Nutrition and Health: IntechOpen; 2019.

34. Younes JA, Lievens E, Hummelen R, van der Westen R, Reid G, Petrova MI. Women and their microbes: the unexpected friendship. Trends Microbiol. 2018;26(1):16-32

35. Ravel J, Gajer P, Abdo Z, Schneider GM, Koenig SSK, McCulle SL, et al. Vaginal microbiome of reproductive-age women. Proc Natl Acad Sci U S A. 2011;108(Suppl 1):4680-7.

36. Diop K, Dufour J-C, Levasseur A, Fenollar F. Exhaustive repertoire of human vaginal microbiota. Hum Microbiome J. 2019;11:100051.

37. Hinderfeld AS, Phukan N, Bär A-K, Roberton AM, Simoes-Barbosa A. Cooperative interactions between Trichomonas vaginalis and associated bacteria enhance paracellular permeability of the cervicovaginal epithelium by dysregulating tight junctions. Infect Immun. 2019:87(5):e00141-19.

38. Boris $\mathrm{S}$, Barbés $\mathrm{C}$. Role played by lactobacilli in controlling the population of vaginal pathogens. Microbes Infect. 2000;2(5):543-6.

39. Bouchemal K, Bories C, Loiseau PM. Strategies for prevention and treatment of Trichomonas vaginalis infections. Clin Microbiol Rev. 2017;30(3):811-25.

40. Phukan N, Brooks AES, Simoes-Barbosa A. A cell surface aggregationpromoting factor from Lactobacillus gasseri contributes to inhibition of Trichomonas vaginalis adhesion to human vaginal ectocervical cells. Infect Immun. 2018;86(8):e00907-17.

41. Brotman RM, Bradford LL, Conrad M, Gajer P, Ault K, Peralta L, et al. Association between Trichomonas vaginalis and vaginal bacterial community composition among reproductive-age women. Sex Transm Dis. 2012;39(10):807-12.

42. Valadkhani Z, Hassan N. Z a, Mostafavi E. protective role of Lactobacillus acidophilus against vaginal infection with Trichomonas vaginalis. Mediterr J Biosci. 2016;1:50-4.

43. Bertini M. Bacterial vaginosis and sexually transmitted diseases. In: Serdaroglu S, Kutlubay Z, editors. Relationship and Management, Fundamentals of Sexually Transmitted Infections: IntechOpen; 2017. https:// doi.org/10.5772/intechopen.69258.

44. Friedman M, Kozukue N, Kim H-J, Choi S-H, Mizuno M. Glycoalkaloid, phenolic, and flavonoid content and antioxidative activities of conventional nonorganic and organic potato peel powders from commercial gold, red, and russet potatoes. J Food Compos Anal. 2017;62:69-75.
45. Friedman M, Lee KR, Kim HJ, Lee IS, Kozukue N. Anticarcinogenic effects of glycoalkaloids from potatoes against human cervical, liver, lymphoma, and stomach cancer cells. J Agric Food Chem. 2005;53(15):6162-9.

46. Friedman M. Chemistry and anticarcinogenic mechanisms of glycoalkaloids produced by eggplants, potatoes, and tomatoes. J Agric Food Chem. 2015; 63(13):3323-37.

47. Elkahoui S, Bartley GE, Yokoyama WH, Friedman M. Dietary supplementation of potato peel powders prepared from conventional and organic russet and nonorganic gold and red potatoes reduces weight gain in mice on a highfat diet. J Agric Food Chem. 2018;66(24):6064-72.

48. Blankemeyer JT, White JB, Stringer BK, Friedman M. Effect of a-tomatine and tomatidine on membrane potential of frog embryos and active transport of ions in frog skin. Food Cheml Toxicol. 1997;35(7):639-46.

49. Blankemeyer JT, Atherton R, Friedman M. Effect of potato glycoalkaloids achaconine and a-solanine on sodium active-transport in frog-skin. J Agric Food Chem. 1995;43(3):636-9.

50. de Groot C, Müller-Goymann CC. Saponin interactions with model membrane systems - langmuir monolayer studies, hemolysis and formation of ISCOMs. Planta Med. 2016;82(18):1496-512.

51. Kozukue N, Han J-S, Lee K-R, Friedman M. Dehydrotomatine and a-tomatine content in tomato fruits and vegetative plant tissues. J Agric Food Chem. 2004;52(7):2079-83.

52. Friedman M, Kozukue N, Mizuno M, Sakakibara H, Choi S-H, Fujitake M, et al. The analysis of the content of biologically active phenolic compounds, flavonoids, and glycoalkaloids in harvested red, yellow, and green tomatoes, tomato leaves, and tomato stems. Curr Top Phytochem. 2019;15:43-53.

53. Friedman M, Fitch TE, Yokoyama WE. Lowering of plasma LDL cholesterol in hamsters by the tomato glycoalkaloid tomatine. Food Cheml Toxicol. 2000; 38(7):549-53.

54. Friedman M, McQuistan T, Hendricks JD, Pereira C, Bailey GS. Protective effect of dietary tomatine against dibenzo [a,] pyrene (DBP)-induced liver and stomach tumors in rainbow trout. Mol Nutr Food Res. 2007:51(12):1485-91.

55. Kim SP, Nam SH, Friedman M. The tomato glycoalkaloid a-tomatine induces caspase-independent cell death in mouse colon cancer CT-26 cells and transplanted tumors in mice. J Agric Food Chem. 2015;63(4):1142-50.

56. Choi S-H, Lee S-H, Kim H-J, Lee I-S, Kozukue N, Levin CE, et al. Changes in free amino acid, phenolic, chlorophyll, carotenoid, and glycoalkaloid contents in tomatoes during 11 stages of growth and inhibition of cervical and lung human cancer cells by green tomato extracts. J Agric Food Chem. 2010;58(13):7547-56.

57. Friedman $\mathrm{M}$, Levin CE. a-Tomatine content in tomato and tomato products determined by HPLC with pulsed amperometric detection. J Agric Food Chem. 1995;43(6):1507-11.

58. Chen Y, Li S, Sun F, Han H, Zhang X, Fan Y, et al. In vivo antimalarial activities of glycoalkaloids isolated from Solanaceae plants. Pharm Biol. 2010; 48(9):1018-24.

59. Thorne HV, Clarke GF, Skuce R. The inactivation of herpes simplex virus by some Solanaceae glycoalkaloids. Antivir Res. 1985;5(6):335-43.

60. Schedin-Weiss S, Gaunitz S, Sui P, Chen Q, Haslam SM, Blennow K, et al. Glycan biomarkers for Alzheimer disease correlate with T-tau and P-tau in cerebrospinal fluid in subjective cognitive impairment. FEBS J. 2020;287(15): 3221-34. https://doi.org/10.1111/febs.15197.

61. Noritake SM, Liu J, Kanetake S, Levin CE, Tam C, Cheng LW, et al. Phytochemical-rich foods inhibit the growth of pathogenic trichomonads. BMC Complement Altern Med. 2017;17(1):461.

62. Friedman M. Overview of antibacterial, antitoxin, antiviral, and antifungal activities of tea flavonoids and teas. Mol Nutr Food Res. 2007;51(1):116-34.

63. Friedman M, Henika PR, Levin CE, Mandrell RE, Kozukue N. Antimicrobial activities of tea catechins and theaflavins and tea extracts against Bacillus cereus. J Food Prot. 2006;69(2):354-61.

64. Friedman M, Mackey BE, Kim H-J, Lee I-S, Lee K-R, Lee S-U, et al. Structureactivity relationships of tea compounds against human cancer cells. J Agric Food Chem. 2007;55(2):243-53.

65. Friedman M, Kim S-Y, Lee S-J, Han G-P, Han J-S, Lee K-R, et al. Distribution of catechins, theaflavins, caffeine, and theobromine in 77 teas consumed in the United States. J Food Sci. 2005;70(9):C550-C9.

66. Friedman M, Levin CE, Choi S-H, Kozukue E, Kozukue N. HPLC analysis of catechins, theaflavins, and alkaloids in commercial teas and green tea dietary supplements: comparison of water and $80 \%$ ethanol/water extracts. J Food Sci. 2006;71(6):C328-37. 
67. Sirk TW, Brown EF, Friedman M, Sum AK. Molecular binding of catechins to biomembranes: relationship to biological activity. J Agric Food Chem. 2009; 57(15):6720-8

68. Sirk TW, Brown EF, Sum AK, Friedman M. Molecular dynamics study on the biophysical interactions of seven green tea catechins with lipid bilayers of cell membranes. J Agric Food Chem. 2008;56(17):7750-8.

69. Sirk TW, Friedman M, Brown EF. Molecular binding of black tea theaflavins to biological membranes: relationship to bioactivities. J Agric Food Chem. 2011;59(8):3780-7

70. Moon T, Wilkinson JM, Cavanagh HMA. Antiparasitic activity of two Lavandula essential oils against Giardia duodenalis, Trichomonas vaginalis and Hexamita inflata. Parasitol Res. 2006;99(6):722-8.

71. Cheikh-Ali Z, Adiko M, Bouttier S, Bories C, Okpekon T, Poupon E, et al. Composition, and antimicrobial and remarkable antiprotozoal activities of the essential oil of rhizomes of Aframomum sceptrum K. Schum. (Zingiberaceae). Chem Biodivers. 2011;8(4):658-67.

72. Akram Khan M, Afzal M. Chemical composition of Nigella sativa Linn: part 2 recent advances. Inflammopharmacology. 2016;24(2):67-79.

73. Shaikh S, Aaqil H, Rizvi SM, Shakil S, Abuzenadah AM, Gupta P, et al. Comparative inhibition study of compounds identified in the methanolic extract of Apamarga Kshara against Trichomonas vaginalis carbamate kinase (TVCK): an enzoinformatics approach. Interdiscip Sci. 2016;8(4):357-65.

74. Oliveira FS, Freitas TSd, Cruz RPd, Costa MdS, Pereira RLS, Quintans-Júnior LJ, et al. Evaluation of the antibacterial and modulatory potential of abisabolol, $\beta$-cyclodextrin and a-bisabolol/ $\beta$-cyclodextrin complex. Biomed Pharmacother. 2017;92:1111-8.

75. Friedman M. Antimicrobial activities of plant essential oils and their components against antibiotic-susceptible and antibiotic-resistant foodborne pathogens. In: Rai M, Zachino S, Derita MD, editors. Essential oils and nanotechnology for treatment of microbial diseases. Boca Raton, Florida: CRC Press; 2017. p. 14-38.

76. Friedman M, Henika PR, Mandrell RE. Bactericidal activities of plant essential oils and some of their isolated constituents against Campylobacter jejuni, Escherichia coli, Listeria monocytogenes, and Salmonella enterica. J Food Prot. 2002;65(10):1545-60.

77. Friedman M, Henika PR, Levin CE, Mandrell RE. Antibacterial activities of plant essential oils and their components against Escherichia coli O157:H7 and Salmonella enterica in apple juice. J Agric Food Chem. 2004;52(19):6042-8.

78. Chen CH, Ravishankar S, Marchello J, Friedman M. Antimicrobial activity of plant compounds against Salmonella Typhimurium DT104 in ground pork and the influence of heat and storage on the antimicrobial activity. J Food Prot. 2013;76(7):1264-9

79. Todd J, Friedman M, Patel J, Jaroni D, Ravishankar S. The antimicrobial effects of cinnamon leaf oil against multi-drug resistant Salmonella Newport on organic leafy greens. Int J Food Microbiol. 2013;166(1):193-9.

80. Sinha S, Prakash A, Sehgal R, Medhi B. Comparative effect of manuka honey on anaerobic parasitic protozoans with standard drug therapy under in vitro conditions: a preliminary study. Indian J Pharmacol. 2018;50(4):197-203.

81. Taylor MA, Robertson AW, Biggs PJ, Richards KK, Jones DF, Parkar SG. The effect of carbohydrate sources: sucrose, invert sugar and components of manuka honey, on core bacteria in the digestive tract of adult honey bees (Apis mellifera). PLoS One. 2019;14(12):e0225845.

82. Friedman M. Antibacterial, antiviral, and antifungal properties of wines and winery byproducts in relation to their flavonoid content. J Agric Food Chem. 2014;62(26):6025-42.

83. Rauf A, Imran M, Butt MS, Nadeem M, Peters DG, Mubarak MS. Resveratrol as an anti-cancer agent: a review. Crit Rev Food Sci Nutr. 2018;58(9):1428-47.

84. Xia N, Daiber A, Förstermann U, Li H. Antioxidant effects of resveratrol in the cardiovascular system. Br J Pharmacol. 2017;174(12):1633-46.

85. Moo-Puc R, Robledo D, Freile-Pelegrin Y. Evaluation of selected tropical seaweeds for in vitro anti-trichomonal activity. J Ethnopharmacol. 2008;120(1):92-7.

86. Cantillo-Ciau Z, Moo-Puc R, Quijano L, Freile-Pelegrín Y. The tropical brown alga Lobophora variegata: a source of antiprotozoal compounds. Marine Drugs. 2010;8(4):1292-304.

87. Scopel M, dos Santos O, Frasson AP, Abraham W-R, Tasca T, Henriques AT, et al. Anti-Trichomonas vaginalis activity of marine-associated fungi from the south Brazilian coast. Exp Parasitol. 2013;133(2):211-6.

88. Muelas-Serrano S, Nogal JJ, Martinez-Diiaz RA, Escario JA, MartinezFernandez AR, Gómez-Barrio A. In vitro screening of American plant extracts on Trypanosoma cruzi and Trichomonas vaginalis. J Ethnopharmacol. 2000; $71(1): 101-7$
89. Calzada F, Yépez-Mulia L, Tapia-Contreras A. Effect of Mexican medicinal plant used to treat trichomoniasis on Trichomonas vaginalis trophozoites. Ethnopharmacol. 2007;113(2):248-51.

90. Soh PN, Benoit-Vical F. Are west African plants a source of future antimalarial drugs? J Ethnopharmacol. 2007;114(2):130-40.

91. Ziaei Hezarjaribi H, Nadeali N, Fakhar M, Soosaraei M. Medicinal plants with anti-Trichomonas vaginalis activity in Iran: a systematic review. Iran J Parasitol. 2019;14(1):1-9.

92. Moraes MEA, Cunha GH, Bezerra MM, Fechine FV, Pontes AV, Andrade WS, et al. Efficacy of the Mentha crispa in the treatment of women with Trichomonas vaginalis infection. Arch Gynecol Obstet. 2012;286(1):125-30.

93. Teles NSB, Fechine FV, Viana FAC, Viana IOL, Nascimento DF, Leite ALAS, et al. Evaluation of the therapeutic efficacy of Mentha crispa in the treatment of giardiasis. Contemp Clin Trials. 2011;32(6):809-13.

94. Abdali K, Jahed L, Amooee S, Zarshenas M, Tabatabaee H, Bekhradi R. Comparison of the effect of vaginal Zataria multiflora cream and oral metronidazole pill on results of treatments for vaginal infections including trichomoniasis and bacterial vaginosis in women of reproductive age. BioMed Res Int. 2015;2015:683640.

95. Sgibnev A, Kremleva E. Probiotics in addition to metronidazole for treatment Trichomonas vaginalis in the presence of BV: a randomized, placebo-controlled, double-blind study. Eur J Clin Microbiol Infect Dis. 2020;39(2):345-51.

96. Aslani A, Asghari G, Darani HY, Ghanadian M, Hosseini F. Design, formulation, and physicochemical evaluation of vaginal cream containing Eucalyptus camaldulensis, Viola odorata, and Mentha piperita extracts for prevention and treatment of Trichomoniasis. Int J Prev Med. 2019;10:179.

97. Iwanowycz S, Wang J, Hodge J, Wang Y, Yu F, Fan D. Emodin inhibits breast cancer growth by blocking the tumor-promoting feedforward loop between cancer cells and macrophages. Mol Cancer Ther. 2016;15(8):1931-42.

98. Alves DS, Pérez-Fons L, Estepa A, Micol V. Membrane-related effects underlying the biological activity of the anthraquinones emodin and barbaloin. Biochem Pharmacol. 2004;68(3):549-61.

99. Ji X, Liu X, Peng Y, Zhan R, Xu H, Ge X. Comparative analysis of methicillinsensitive and resistant Staphylococcus aureus exposed to emodin based on proteomic profiling. Biochem Biophys Res Commun. 2017;494(1):318-24.

100. Song C, Liu B, Xu P, Ge X, Zhang H. Emodin ameliorates metabolic and antioxidant capacity inhibited by dietary oxidized fish oil through PPARs and Nrf2-Keap1 signaling in Wuchang bream (Megalobrama amblycephala). Fish Shellfish Immunol. 2019;94:842-51.

101. Cobo ER, Eckmann L, Corbeil LB. Murine models of vaginal trichomonad infections. The American Journal of Tropical Medicine and Hygiene. 2011; 85(4):667-73.

102. Hopper M, Yun J-f, Zhou B, Le C, Kehoe K, Le R, et al. Auranofin inactivates Trichomonas vaginalis thioredoxin reductase and is effective against trichomonads in vitro and in vivo. Int J Antimicrob Agents. 2016;48(6):690-4

103. Friedman M, Xu A, Lee R, Nguyen DN, Phan TA, Hamada SM, et al. The inhibitory activity of anthraquinones against pathogenic protozoa, bacteria, and fungi and the relationship to structure. Molecules. 2020;25(13):3101. https://doi.org/10.3390/molecules25133101.

104. Nam W, Kim SP, Nam S-H, Friedman M. Structure-antioxidative and antiinflammatory activity relationships of purpurin and related anthraquinones in chemical and cell assays. Molecules. 2017;22(2):265.

105. Nam W, Nam SH, Kim SP, Levin C, Friedman M. Anti-adipogenic and antiobesity activities of purpurin in 3T3-L1 preadipocyte cells and in mice on a high-fat diet. BMC Complement Altern Med. 2019;19(1):364

106. Giordani RB, PdB V, Weizenmann M, Rosemberg DB, Souza AP, Bonorino C, et al. Lycorine induces cell death in the amitochondriate parasite, Trichomonas vaginalis, via an alternative non-apoptotic death pathway. Phytochemistry. 2011;72(7):645-50.

107. Giordani RB, Junior COR, de Andrade JP, Bastida J, Zuanazzi JAS, Tasca T, et al. Lycorine derivatives against Trichomonas vaginalis. Chem Biol Drug Des. 2012;80(1):129-33.

108. Petro-Silveira B, Rigo GV, da Silva TD, Macedo AJ, Sauer E, de Oliveira AE, et al. Trichomonas vaginalis NTPDase inhibited by lycorine modulates the parasite-neutrophil interaction. Parasitol Res. 2020;119(8):2587-95.

109. Vilela R, Menna-Barreto RFS, Benchimol M. Methyl jasmonate induces cell death and loss of hydrogenosomal membrane potential in Trichomonas vaginalis. Parasitol Int. 2010;59(3):387-93.

110. Gunjegaonkar SM, Shanmugarajan TS. Molecular mechanism of plant stress hormone methyl jasmonate for its anti-inflammatory activity. Plant Signal Behav. 2019;14(10):e1642038. 
111. Vieira PB, Silva NLF, da Silva GNS, Silva DB, Lopes NP, Gnoatto SCB, et al. Caatinga plants: natural and semi-synthetic compounds potentially active against Trichomonas vaginalis. Bioorg Med Chem Lett. 2016;26(9):2229-36.

112. Hübner DPG, de Brum Vieira P, Frasson AP, Menezes CB, Senger FR, Santos da Silva GN, et al. anti-Trichomonas vaginalis activity of betulinic acid derivatives. Biomed Pharmacother. 2016;84:476-84.

113. Jain A, Kumar L, Kushwaha B, Sharma M, Pandey A, Verma V, et al. Combining a synthetic spermicide with a natural trichomonacide for safe, prophylactic contraception. Hum Reprod. 2013;29(2):242-52.

114. de Brum VP, Silva NLF, Menezes CB, da Silva MV, Silva DB, Lopes NP, et al. Trichomonicidal and parasite membrane damaging activity of bidesmosic saponins from Manilkara rufula. Plos One. 2017;12(11):e0188531.

115. Patridge EV, Darnell A, Kucera K, Phillips GM, Bokesch HR, Gustafson KR, et al. Pyrrolocin a, a 3-decalinoyltetramic acid with selective biological activity, isolated from Amazonian cultures of the novel endophyte Diaporthales sp. E6927E. Nat Prod Commun. 2015;10(10):1649-54.

116. Friedman M. Antibiotic-resistant bacteria: prevalence in food and inactivation by food-compatible compounds and plant extracts. J Agric Food Chem. 2015;63(15):3805-22.

117. Kim SP, Lee SJ, Nam SH, Friedman M. Mechanism of antibacterial activities of a rice hull smoke extract (RHSE) against multidrug-resistant Salmonella Typhimurium in vitro and in mice. J Food Sci. 2018;83(2):440-5.

118. da Silva NS, Ribeiro Cde M, Machado AH, Pacheco-Soares C. Ultrastructural changes in Tritrichomonas foetus after treatments with AIPCS4 and photodynamic therapy. Vet Parasitol. 2007;146(1-2):175-81.

119. Silva Fonseca $T H$, Alacoque M, Silva Oliveira FM, Soares BM, Leite HV, Caliari MV, et al. Photodynamic therapy as a new approach to Trichomonas vaginalis inactivation. Photodiagn Photodyn Ther. 2018;22:91-5.

120. Dirkx M, Boyer MP, Pradhan P, Brittingham A, Wilson WA. Expression and characterization of a $\beta$-fructofuranosidase from the parasitic protist Trichomonas vaginalis. BMC Biochem. 2014;15(1):12

121. Puente-Rivera J, Villalpando JL, Villalobos-Osnaya A, Vázquez-Carrillo LI, León-Ávila G, Ponce-Regalado MD, et al. The 50kDa metalloproteinase TvMP50 is a zinc-mediated Trichomonas vaginalis virulence factor. Mol Biochem Parasitol. 2017;217:32-41.

122. Arreola R, Villalpando JL, Puente-Rivera J, Morales-Montor J, Rudiño-Piñera E, Alvarez-Sánchez ME. Trichomonas vaginalis metalloproteinase TvMP50 is a monomeric Aminopeptidase P-like enzyme. Mol Biotechnol. 2018;60(8):563-75.

123. Quan J-H, Kang B-H, Yang J-B, Rhee Y-E, Noh H-T, Choi I-W, et al. Trichomonas vaginalis induces $\mathrm{SiHa}$ cell apoptosis by NF-KB inactivation via reactive oxygen species. BioMed Res Int. 2017;2017:3904870.

124. Sharma M, Kumar L, Jain A, Verma V, Sharma V, Kushwaha B, et al. Designed chemical intervention with thiols for prophylactic contraception. Plos One. 2013;8(6):e67365.

125. Friedman M, Gumbmann MR, Grosjean OK. Nutritional improvement of soy flour. J Nutr. 1984;114(12):2241-6.

126. Friedman M. The chemistry and biochemistry of the sulfhydryl Group in Amino Acids, peptides, and proteins. Oxford, England: Pergamon Press; 1973. 499 p.

127. Rayburn JR, Friedman M. L-cysteine, N-acetyl-L-cysteine, and glutathione protect Xenopus laevis embryos against acrylamide-induced malformations and mortality in the frog embryo Teratogenesis assay. J Agric Food Chem. 2010;58(20):11172-8.

128. Williams JR, Rayburn JR, Cline GR, Sauterer R, Friedman M. The potential protective effect of $L$-cysteine against the toxicity of acrylamide and furan in exposed Xenopus laevis embryos: an interaction study. J Agric Food Chem. 2014;62(31):7927-38.

129. Trein MR, Rodrigues e Oliveira L, Rigo GV, Garcia MAR, Petro-Silveira B, da Silva Trentin D, et al. anti-Trichomonas vaginalis activity of chalcone and amino-analogues. Parasitol Res 2019;118(2):607-615.

130. Nozaki T, Ali V, Tokoro M. Sulfur-containing amino acid metabolism in parasitic protozoa. In: Baker JR, Muller R, Rollinson D, editors. Advances in Parasitology, vol. 60: Academic Press; 2005. p. 1-99. https:/doi.org/10.1016/S0065-308X(05)60001-2.

131. Westrop GD, Wang L, Blackburn GJ, Zhang T, Zheng L, Watson DG, et al. Metabolomic profiling and stable isotope labelling of Trichomonas vaginalis and Tritrichomonas foetus reveal major differences in amino acid metabolism including the production of 2-hydroxyisocaproic acid, cystathionine and S-methylcysteine. Plos One. 2017;12(12):e0189072.

132. Rigo GV, Trein MR, da Silva TD, Macedo AJ, de Oliveira BA, de Almeida AM, et al. Diamine derivative anti-Trichomonas vaginalis and anti-Tritrichomonas foetus activities by effect on polyamine metabolism. Biomed Pharmacother. 2017;95:847-55.
133. Bradic M, Warring SD, Tooley GE, Scheid P, Secor WE, Land KM, et al. Genetic indicators of drug resistance in the highly repetitive genome of Trichomonas vaginalis. Genome Biol Evol. 2017;9(6):1658-72.

134. Friedman M. Tomato glycoalkaloids: role in the plant and in the diet. J Agric Food Chem. 2002;50(21):5751-80

135. Zhao X, Lu L, Qi Y, Li M, Zhou L. Emodin extends lifespan of Caenorhabditis elegans through insulin/IGF-1 signaling pathway depending on DAF-16 and SIR-2.1. Biosci Biotechnol Biochem. 2017:81(10):1908-16.

136. Enioutina EY, Salis ER, Job KM, Gubarev MI, Krepkova LV, Sherwin CM. Herbal medicines: challenges in the modern world. Part 5. Status and current directions of complementary and alternative herbal medicine worldwide. Expert Rev Clin Pharmacol. 2017;10(3):327-38.

\section{Publisher's Note}

Springer Nature remains neutral with regard to jurisdictional claims in published maps and institutional affiliations.
Ready to submit your research? Choose BMC and benefit from:

- fast, convenient online submission

- thorough peer review by experienced researchers in your field

- rapid publication on acceptance

- support for research data, including large and complex data types

- gold Open Access which fosters wider collaboration and increased citations

- maximum visibility for your research: over $100 \mathrm{M}$ website views per year

At BMC, research is always in progress.

Learn more biomedcentral.com/submissions 